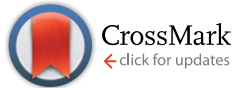

Cite this: RSC Adv., 2017, 7, 4763

Received 9th October 2016 Accepted 28th November 2016

DOI: $10.1039 / c 6 r a 24953 a$

www.rsc.org/advances

\section{Substituted 4-oxo-crotonic acid derivatives as a new class of protein kinase B (PknB) inhibitors: synthesis and SAR study $\dagger$}

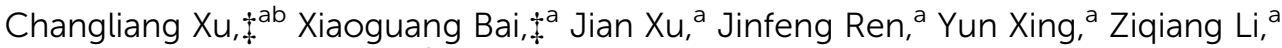 \\ Juxian Wang, ${ }^{a}$ Jingjing Shi, ${ }^{b}$ Liyan Yu*a and Yucheng Wang*a
}

Protein kinase $B(P k n B)$ is an essential serine/threonine protein kinase required for Mycobacterium tuberculosis $(M . t b)$ cell division and cell-wall biosynthesis. A high throughput screen using PknB identified a (E)-4-oxo-crotonic acid inhibitor, named $\mathrm{YH}-8$, which was used as a scaffold for SAR investigations. A significant improvement in enzyme affinity was achieved. The results indicated that the $\alpha, \beta$-unsaturated ketone scaffold and "trans-" configuration are essential for the activity against PknB. And compounds with an aryl group, especially with electron-withdrawing substituents on benzene ring, exhibited four fold potency than that of $\mathrm{YH}-8$.

\section{Introduction}

As an essential Mycobacterium tuberculosis (Mtb) serine/ threonine protein kinase (STPK), protein kinase B ( $\mathrm{PknB}$ ) is highly conserved in Gram-positive bacteria and apparently required for mycobacterial growth. ${ }^{1-4}$ The knockout and overexpression of PknB can lead to alteration of growth rate and cell morphology of TB. ${ }^{5-8}$ The crystal structure of the kinase domain of PknB in complexes with an ATP analogue ${ }^{9}$ exhibits less than $30 \%$ similarity with eukaryotic and prokaryotic STPKs, which suggests that PknB may be a potential drug target for the tuberculosis kinases and not those of the host. Previously many high affinity inhibitors have also been reported for PknB. ${ }^{10}$

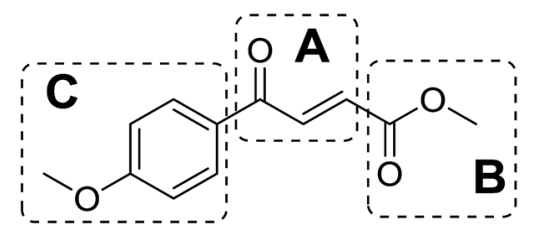

Fig. 1 The HTS hit YH-8.

\footnotetext{
anstitute of Medicinal Biotechnology, Chinese Academy of Medical Science, Peking Union Medical College, Beijing 100050, China.E-mail: yly@cpcc.ac.cn; wyc9999@ gmail.com; Fax: +86-010-6318-7118; +86-010-6316-5263; Tel: +86-010-6318-7118; $+86-010-6316-5263$

Jjiangsu Protein Drug Engineering Laboratory, Food \& Drug Analysis and Testing Center, Jiangsu Food \& Pharmaceutical Science College, Huai'an 223003, Jiangsu, China. E-mail: clxu1986@163.com; Tel: +86-0517-87088209

$\dagger$ Electronic supplementary information (ESI) available: NMR spectra of synthesized compounds. See DOI: 10.1039/c6ra24953a

\$ These authors contributed equally to this work.
}

YH-8, namely (E)-methyl-4-(4-methoxyphenyl)-4-oxobut-2enoate (Fig. 1), was identified as a PknB inhibitor from a high throughput screen (HTS) of our compounds collection. Its majority anti-TB activity of minimum inhibitory concentrations (MICs) is falling in the $0.625-1.250 \mu \mathrm{mol} \mathrm{L} \mathrm{L}^{-1}$ range in vitro, which is significantly higher than other reported PknB inhibitors, such as amminopyrimidines, aminoguanidines and anthraquinones classes..$^{11}$ Stability assay revealed that $\mathbf{Y H - 8}$ was stable over $12 \mathrm{~h}$ in rat plasma samples, and the acute toxicity for the $\mathrm{LD}_{50}$ values in rat were $600 \mathrm{mg} \mathrm{kg}{ }^{-1}$ (orally administered) and $200 \mathrm{mg} \mathrm{kg}^{-1}$ (vein injected). ${ }^{12}$ As a new unsaturated crotonic acid scaffold of YH-8 from all reported anti-TB chemical scaffolds, ${ }^{10,13}$ the previously results formed the starting point for our chemistry programme. In this study, we reported on the synthesis and structure-activity relationship (SAR) study of series of YH-8 derivatives as potential PknB inhibitors.

\section{Chemical synthesis}

In Scheme 1, 7 compounds were firstly designed and synthesized based on the scaffold A $((E)$ - $\alpha, \beta$-unsaturated ketone, Fig. 1) of YH-8 for SAR investigations. $\gamma$-Oxobenzenebutanoic acid 2a was prepared using Friedel-Crafts acylation of anisole with succinic anhydride catalyzed by Lewis acid of aluminum chloride in $80 \%$ yield. ${ }^{14}$ Reduction of $\mathbf{2 a}$ by triethylsilane in trifluoroacetic acid obtained 3a in 72\% yield. Methyl esters 1b, $\mathbf{2 b}$ and $\mathbf{3 b}$ were synthesized from corresponding acids $\mathbf{1 a}, \mathbf{2} \mathbf{a}$ and 3a in methanol catalyzed by concentrated sulfuric acid in $92-$ 95\% yields. ${ }^{15}$ According to literature method, ${ }^{16}$ the carboxylic acid group of 1a, 2a and 3a was firstly activated by treatment with isobutylchloroformate (IBCF), the product of which was then treated in situ with ammonia gas at $-15{ }^{\circ} \mathrm{C}$ to give corresponding amides 1c, $2 \mathbf{c}$ and $3 \mathbf{c}$ in $75-85 \%$ yields. In Scheme 2, 
(a)<smiles>COc1ccc(/C=C/C(=O)O)cc1</smiles><smiles>CCOc1ccc(/C=C/C(=O)OC)cc1</smiles>

(b)

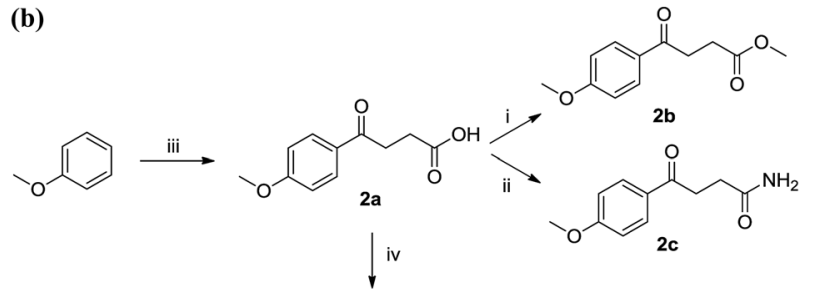<smiles>COC(=O)CCCc1ccc(OC)cc1</smiles>

(c)

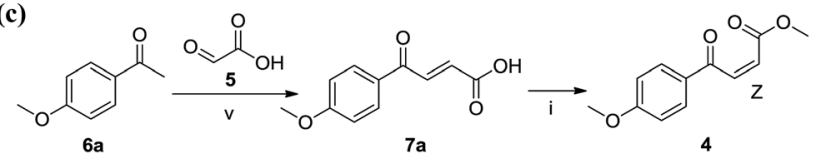

Scheme 1 (a-c) Synthesis of compounds $1 a-c, 2 a-c, 3 a-c$ and 4 Regents and conditions: (i) $\mathrm{MeOH}$, sulfuric acid (Cat.), reflux, overnight; (ii) IBCF, TEA, anhydrous THF, $-15^{\circ} \mathrm{C}, 1 \mathrm{~h}$, then $\mathrm{NH}_{3}(\mathrm{~g}), 0^{\circ} \mathrm{C}$, overnight: (iii) succinic anhydride, $\mathrm{AlCl}_{3}$, nitrobenzene, $0^{\circ} \mathrm{C}$ to $\mathrm{rt}, 1 \mathrm{~h}$, then $60^{\circ} \mathrm{C}$, $3 \mathrm{~h}$; (iv) triethylsilane, TFA, $50^{\circ} \mathrm{C}, 5 \mathrm{~h}$; (v) acetic acid, reflux, overnight.

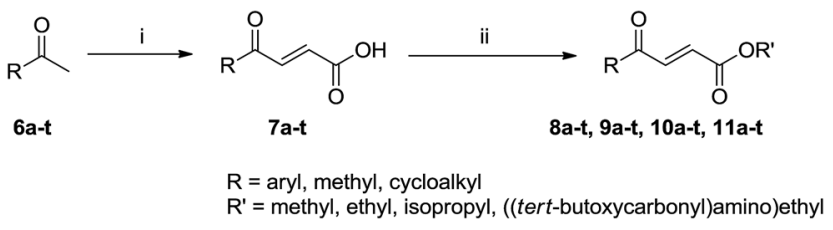

Scheme 2 Synthesis of compounds $8 a-t, 9 a-t, 10 a-t$, and 11a-t Regents and conditions: (i) glyoxylic acid, acetic acid, reflux, overnight, for $7 \mathrm{a}-\mathrm{r}$ and $7 \mathrm{t}$; glyoxylic acid, morpholine hydrochloride (Cat.), $120^{\circ} \mathrm{C}$, overnight, for $7 \mathrm{~s}$; (ii) $\mathrm{R}^{\prime} \mathrm{OH}$, sulfuric acid (Cat.), reflux, overnight, for $8 \mathrm{a}-\mathrm{t}, 9 \mathrm{a}-\mathrm{t}, 10 \mathrm{a}-\mathrm{t}$; IBCF, TEA, anh. DCM, $-15^{\circ} \mathrm{C}, 8 \mathrm{~h}$, then $\mathrm{N}$-Bocethanolamine, rt, overnight, for 11a-t.

the 20 aromatic E-3-acylacrylic acid derivatives $7 \mathbf{a}-\mathbf{t}$ were directly prepared from corresponding ketones $\mathbf{6 a - t}$ and glyoxylic acid in 50-75\% yields. ${ }^{17}$ Esters $8 \mathbf{8}-\mathbf{t}$, 9a-t and 10a-t were obtained using the same method of $2 \mathrm{a}$ in around $40 \%$ yield. The "cis-" configuration (4, (Z)-methyl 4-(4-methoxyphenyl)-4oxobut-2-enoate) of YH-8 (8a) was separated from a mixture of cis- and trans-products in $48 \%$ yield. Similarly, the carboxylic acid group of $7 \mathbf{a}-\mathbf{t}$ was firstly activated by treatment with IBCF, the product of which was then treated in situ with $\mathrm{N}$-Bocethanolamine to afford compounds 11a-t in $47-84 \%$ yields.

\section{Results and discussion}

As a promising PknB inhibitor, the structure of YH-8 is markedly different from the reported PknB inhibitors. As shown in Fig. 1, YH-8 was characterized as a substituted (E)-4-oxocrotonic acid scaffold with three parts, namely $\mathrm{A}((E)-\alpha, \beta-$ unsaturated ketone), B (ester) and C (aryl). We presumed each part should play a different role of the interactions between YH8 and PknB ATP-binding site. In other words, firstly we should clarify which part is essential for the activity and which part is allowed to be modified for increasing potency. So, initial SAR study was performed mainly around the scaffold $\mathrm{A}((E)-\alpha, \beta$ unsaturated ketone). As shown in Scheme 1-a, scaffold A was firstly deduced to methyl ester $\mathbf{1 b}$ and amide $\mathbf{1 c}$ from corresponding acid 1a, which lacks a carbonyl (ketone) group comparing with the $\alpha, \beta$-unsaturated ketone of A. In Scheme 1-b, the carbon-carbon double bond of scaffold A was deduced to an alkane acid 2a by a Friedel-Crafts acylation reaction from anisole. The carbonyl (ketone) group of 2a was sequentially reduced to methylene of $\mathbf{3 a}$. Both acids of $\mathbf{2 a}$ and $3 \mathbf{a}$ were also converted to corresponding methyl esters $\mathbf{2 b} \& \mathbf{b} \mathbf{b}$ and amides 2c \& 3c. In Scheme 1-c, the "cis-" configuration (4) of YH-8, (Z)methyl 4-(4-methoxyphenyl)-4-oxobut-2-enoate, was separated from a mixture of cis- and trans-products and characterized by ${ }^{1} \mathrm{H}$ NMR. The $J_{\mathrm{HH}}$ of "cis-" configuration is $3.6 \mathrm{~Hz}$ less than its "trans-" configuration. And the "cis-" configuration (4) is a yellow oil, whereas $\mathbf{Y H - 8}$, namely $\mathbf{8 a}$ in this study, is a yellow solid.

According to preliminary measurements, inhibitor concentration of $20 \mu \mathrm{M}$ in the assay of percent inhibition of PknB was selected mainly because this concentration can cover and reflect the inhibitory rates rightly for all test compounds. Including carboxylic acid, esters and amides, ten compounds in Scheme 1 were tested for inhibitory activity against PknB at $20 \mu \mathrm{M}$ along with YH-8. As shown in Table 1, eight compounds exhibit less than $10 \%$ inhibition against PknB comparing with YH-8 (52.1\%). Only compounds 1 a \& 4 have a moderate inhibition $(30.7 \% \& 24.7 \%)$. The results show the $\alpha, \beta$-unsaturated ketone

Table 1 Inhibitory activity of $1 a-c, 2 a-c, 3 a-c$ and 4 against PknB

\begin{tabular}{|c|c|c|c|c|c|}
\hline Compd. & Inhibition $^{a}(\%)$ & Compd. & Inhibition $^{a}(\%)$ & Compd. & Inhibition $^{a}(\%)$ \\
\hline $1 a$ & $30.7 \pm 1.6$ & $2 \mathbf{a}$ & $3.3 \pm 0.2$ & $3 a$ & $7.0 \pm 0.5$ \\
\hline $1 b$ & $1.7 \pm 0.2$ & $2 b$ & $5.1 \pm 1.6$ & $3 \mathbf{b}$ & $5.6 \pm 0.5$ \\
\hline $1 c$ & $5.4 \pm 0.6$ & $2 c$ & $8.7 \pm 0.6$ & $3 c$ & $8.0 \pm 0.7$ \\
\hline YH-8 (8a) & $52.1 \pm 1.8$ & 4 & $24.7 \pm 1.5$ & & \\
\hline
\end{tabular}

${ }^{a}$ Values represent the percent inhibition of PknB at $20 \mu \mathrm{M}$ of the test compounds and are means of three independent experiments. 
Table 2 The structures of $8 a-t, 9 a-t, 10 a-t$ \& 11a-t<smiles>[R]C(=O)C=CC([R])=O</smiles>

\begin{tabular}{|c|c|c|c|c|}
\hline \multirow[b]{2}{*}{$\mathrm{R}$} & \multicolumn{4}{|l|}{$\mathrm{R}^{\prime}$} \\
\hline & $\mathrm{MeO}$ & EtO & i-PrO & $\operatorname{BocNH}\left(\mathrm{CH}_{2}\right)_{2} \mathrm{O}$ \\
\hline
\end{tabular}

.<smiles>[Y]c1ccc(OC)cc1</smiles>

YH-8 (8a)

9a

10a

11a

8b

$9 b$

$10 \mathrm{~b}$

11b

8c

$\overbrace{0}$

8d<smiles>[Y4]c1ccccc1OC</smiles>

$8 e$<smiles>COc1cccc(I)c1</smiles>

8f<smiles>[Y]c1cc(O)ccc1OC</smiles>

$8 g$

1

$8 h$

${ }_{0}^{O}$<smiles>C[As]1C=CC2=C(C=C1)OCC2</smiles>

$8 \mathbf{i}$

$8 \mathbf{j}$

急

$8 \mathbf{k}$

$\mathrm{PhO}^{2-2}$

81<smiles>C[Te]1=CC=Cc2ccccc21</smiles>

$8 m$<smiles>C[As]1C=CC(Cl)=CC1Cl</smiles>

8n<smiles>[Y]c1ccc([N+](=O)[O-])cc1</smiles>

80<smiles>Brc1ccc(I)cc1</smiles>

$8 p$<smiles>Cc1ccco1</smiles>

$8 q$

Me<smiles>CC1(C)CC1</smiles>

$8 \mathbf{r}$

8s

$8 t$

(9c

$9 c$

9d 10d 11d

$9 \mathrm{e} \quad 10 \mathrm{e} \quad 11 \mathrm{e}$

9

$10 f \quad 11 f$

98

$9 h \quad 10 h \quad 11 h$

$\begin{array}{lll}9 \mathrm{i} & 10 \mathrm{i} & 11 \mathrm{i}\end{array}$

$9 j \quad 10 j$

11k

111

$91 \quad 10$

$9 m \quad 10 m \quad 11 m$

9n 10n 11n

$90 \quad 100 \quad 110$

$9 p \quad 10 p \quad 11 p$

$11 q$

$11 r$

$11 s$

$11 t$

$9 q$

scaffold and "trans-" configuration are essential for the activity of YH-8 against PknB.

Based on the findings above, the subsequent SAR study of YH-8 was carried out on modification of part B and C while maintaining the $\alpha, \beta$-unsaturated ketone scaffold and "trans-" configuration. As shown in Scheme 2, series of compounds were synthesized from corresponding methyl ketones (6a-t). The structures of $\mathbf{8 a - t , ~ 9 a - t , ~ 1 0 a - t , ~ a n d ~ 1 1 a - t ~ w e r e ~ s h o w n ~ i n ~ T a b l e ~} 2$ and their PknB inhibitory activities were listed in Table 3. The data indicated that almost half of the tested compounds have comparable activity against PknB comparing with YH-8 (52.1\%). Particularly, compounds 11a-t bearing a tert-butoxycarbonylaminoethyl group on part B generally show higher potency than that of other series. Among them, 11n-p exhibited much better activity $(87.1 \%, 87.9 \%$ and $87.6 \%$, respectively). Mostly, compounds bearing an aryl group on part $\mathrm{C}$ generally show higher potency than that substituted with alkyl analogues $(\mathbf{8 r}-\mathbf{t}$, 9r-t, 10r-t and 11r-t). It indicated that the alkyl group on part $\mathrm{C}$ would be detrimental to the activity. For the aryl substituted compounds, 8-11g (61.4-70.7\%) with 2,5-dimethoxyphenyl, 811h (62.1-68.3\%) with 3,4-dimethoxyphenyl, 8-11m (61.373.6\%) with naphthyl, 8-11n (61.3-73.6\%) except 9n (49.0\%) with 2,4-dichlorophenyl, 8-11o (59.1-87.9\%) with 4-nitrophenyl, 8-11p (64.5-87.6\%) with 4-bromophenyl and 8-11q (60.8-67.0\%) with furyl exhibit higher activity than YH-8 of $52.1 \%$. We speculated that the position of the substituted group on phenyl ring should be one of the factors that influence the binding between inhibitor and PknB ATP-binding site. Meanwhile, electron-withdrawing groups on phenyl ring should be beneficial to the potency. It maybe through the electronwithdrawing effect influence on the conjugation of scaffold A, which is known to be essential for the activity of YH-8 against PknB above.

Finally, the $50 \%$ inhibition concentrations $\left(\mathrm{IC}_{50}\right)$ of compounds 11a-t were tested in Table 4. Among them, compounds 11a-c, f, $\mathbf{g}, \mathbf{i}, \mathbf{m}-\mathbf{q}$ exhibit apparently higher $\mathrm{IC}_{50}$ activities than YH-8. Particularly, compounds 11n, 110 and 11p ( $\mathrm{IC}_{50}: 5.6 \mu \mathrm{M}, 4.4 \mu \mathrm{M}$ and $5.4 \mu \mathrm{M}$, respectively) with electronwithdrawing substituents on benzene ring show about fourfold more potent than that of YH-8 $\left(\mathrm{IC}_{50}: 20.2 \mu \mathrm{M}\right)$. Additionally, most $\mathrm{IC}_{50}$ values of compounds $11 \mathrm{a}-\mathbf{t}$ in Table 4 consistently match with the corresponding inhibitory rates in Table 3. For example, the inhibitory rates of compounds 11o, 11p, 11n, 11f, 11a, 11e and 11t are 87.9\%, 87.6\%, 87.1\%, 66.2\%, 61.6\%, 54.3\% and $40.0 \%$, respectively. And their corresponding $\mathrm{IC}_{50}$ values are $4.4,5.4,5.6,10.5,14.1,19.1$ and $38.4 \mu \mathrm{M}$, respectively.

\section{Conclusions}

In summary, the starting HTS hit of YH-8 was optimized for potency against PknB, and total 87 compounds were synthesized for SAR investigations. The initial SAR study of YH-8 indicated the $\alpha, \beta$-unsaturated ketone scaffold and "trans-" configuration are essential for the activity of YH-8 against PknB. According to this finding, other 80 YH-8 derivatives were synthesized and evaluated. The results showed that the compounds bearing an aryl group on part $\mathrm{C}$ and a tert- 
Table 3 Inhibitory activity of $8 a-t, 9 a-t, 10 a-t$ and $11 a-t$ against PknB

\begin{tabular}{|c|c|c|c|c|c|c|c|}
\hline Compd. & Inhibition $^{a}(\%)$ & Compd. & Inhibition $^{a}(\%)$ & Compd. & Inhibition $^{a}(\%)$ & Compd. & Inhibition $^{a}(\%)$ \\
\hline YH-8 (8a) & $52.1 \pm 1.8$ & 9a & $48.7 \pm 4.9$ & $10 \mathrm{a}$ & $41.1 \pm 3.4$ & $11 \mathrm{a}$ & $61.6 \pm 2.8$ \\
\hline $8 b$ & $47.8 \pm 4.1$ & $9 b$ & $64.3 \pm 7.7$ & $10 \mathrm{~b}$ & $11.2 \pm 1.7$ & $11 b$ & $69.1 \pm 4.5$ \\
\hline $8 d$ & $54.2 \pm 4.8$ & 9d & $47.8 \pm 7.1$ & 10d & $38.0 \pm 4.2$ & 11d & $55.6 \pm 2.7$ \\
\hline $8 \mathrm{e}$ & $62.1 \pm 5.0$ & $9 e$ & $45.3 \pm 3.7$ & $10 \mathrm{e}$ & $56.2 \pm 5.0$ & $11 \mathrm{e}$ & $54.3 \pm 3.7$ \\
\hline $8 f$ & $63.1 \pm 6.8$ & 9f & $55.7 \pm 7.0$ & $10 f$ & $42.6 \pm 2.9$ & $11 f$ & $66.2 \pm 4.9$ \\
\hline $8 i$ & $45.4 \pm 2.8$ & $9 i$ & $51.2 \pm 1.4$ & $10 \mathrm{i}$ & $60.6 \pm 1.7$ & $11 \mathrm{i}$ & $59.0 \pm 4.5$ \\
\hline $8 \mathbf{j}$ & $39.0 \pm 2.7$ & 9j & $45.9 \pm 3.2$ & $10 \mathrm{j}$ & $43.1 \pm 5.9$ & $11 \mathrm{j}$ & $53.8 \pm 5.3$ \\
\hline $8 \mathbf{k}$ & $48.6 \pm 5.4$ & $9 k$ & $45.9 \pm 6.1$ & $10 \mathrm{k}$ & $19.5 \pm 1.9$ & $11 \mathrm{k}$ & $50.6 \pm 5.6$ \\
\hline 81 & $59.1 \pm 4.9$ & 91 & $51.6 \pm 7.8$ & 101 & $45.5 \pm 5.8$ & 111 & $46.0 \pm 2.6$ \\
\hline $8 \mathrm{~m}$ & $62.8 \pm 6.1$ & $9 m$ & $61.3 \pm 4.6$ & $10 \mathrm{~m}$ & $61.6 \pm 3.8$ & $11 \mathrm{~m}$ & $73.6 \pm 4.0$ \\
\hline $8 n$ & $57.0 \pm 6.0$ & $9 n$ & $49.0 \pm 3.9$ & 10n & $57.1 \pm 5.1$ & $11 n$ & $87.1 \pm 4.3$ \\
\hline $8 s$ & $33.2 \pm 2.7$ & 9s & $53.5 \pm 6.8$ & $10 \mathrm{~s}$ & $42.7 \pm 3.2$ & $11 \mathrm{~s}$ & $54.3 \pm 4.0$ \\
\hline $8 t$ & $36.9 \pm 4.0$ & $9 t$ & $33.4 \pm 5.8$ & $10 t$ & $43.7 \pm 2.9$ & $11 t$ & $40.0 \pm 3.4$ \\
\hline
\end{tabular}

${ }^{a}$ Values represent the percent inhibition of $\mathrm{PknB}$ at $20 \mu \mathrm{M}$ of the test compounds and are means of three independent experiments.

Table 4 The $\mathrm{IC}_{50}$ values of $11 \mathrm{a}-\mathrm{t}$ against PknB

\begin{tabular}{lrlllr}
\hline Compd. & $\mathrm{IC}_{50}{ }^{a}(\mu \mathrm{M})$ & Compd. & $\mathrm{IC}_{50}{ }^{a}(\mu \mathrm{M})$ & Compd. & $\mathrm{IC}_{50}{ }^{a}(\mu \mathrm{M})$ \\
\hline 11a & $14.1 \pm 2.7$ & $\mathbf{1 1 h}$ & $17.7 \pm 1.1$ & $\mathbf{1 1 0}$ & $4.4 \pm 0.6$ \\
$\mathbf{1 1 b}$ & $10.2 \pm 1.7$ & $\mathbf{1 1 i}$ & $12.6 \pm 2.7$ & $\mathbf{1 1 p}$ & $5.4 \pm 0.5$ \\
$\mathbf{1 1 c}$ & $7.9 \pm 1.4$ & $\mathbf{1 1 j}$ & $17.3 \pm 2.7$ & $\mathbf{1 1 q}$ & $11.9 \pm 1.7$ \\
$\mathbf{1 1 d}$ & $19.6 \pm 3.8$ & $\mathbf{1 1 k}$ & $18.9 \pm 2.4$ & $\mathbf{1 1 r}$ & $45.5 \pm 5.2$ \\
$\mathbf{1 1 e}$ & $19.1 \pm 1.1$ & $\mathbf{1 1 l}$ & $\mathrm{ND}^{b}$ & $\mathbf{1 1 s}$ & $27.9 \pm 3.0$ \\
$\mathbf{1 1 f}$ & $10.5 \pm 1.7$ & $\mathbf{1 1 m}$ & $10.6 \pm 1.4$ & $\mathbf{1 1 t}$ & $38.4 \pm 3.3$ \\
$\mathbf{1 1 g}$ & $8.1 \pm 0.4$ & $\mathbf{1 1 n}$ & $5.6 \pm 0.7$ & $\mathbf{Y H - 8}$ & $20.2 \pm 0.2$
\end{tabular}

${ }^{a}$ Values are means of three independent experiments. ${ }^{b}$ Not detected.

butoxycarbonyl-aminoethyl group on part B generally showed higher potency than other compounds and YH-8. Among these compounds, 11n-o and 11p with electron-withdrawing substituents on benzene ring exhibited about fourfold more potent than that of $\mathbf{Y H}-\mathbf{8}$.

\section{Experimental section}

\section{Methods and materials}

The chemicals were purchased from Aldrich Chemical Co., Sigma or Chemical Co. THF was distilled under argon from sodium-benzophenone ketyl and $\mathrm{CH}_{2} \mathrm{Cl}_{2}$ was distilled under argon from calcium hydride. The reaction products were purified by crystallization or flash column chromatography using a mixture of petroleum ether and ethyl acetate as the eluent. All melting points were obtained on a Mettler Toledo Melting Point MP70 apparatus (Mettler Toledo, Zurich, Switzerland) and are uncorrected. ${ }^{1} \mathrm{H}-\mathrm{NMR}$ spectra were recorded on Varian Inova$400 \mathrm{MHz}$, Varian Inova-500 $\mathrm{MHz}$ and SYS-600 MHz instruments (Varian, Palo Alto, CA, USA). The chemical shifts $(\delta)$ are reported in ppm relative to the internal reference standard tetramethylsilane (TMS) and the coupling constants ( $J$ values) have been reported in Hertz (Hz). MS data were obtained using time-of-flight mass spectrometer (TOF-MS) or Bruker microTOF-Q instrument (Bruker, Billerica, MA, USA). High resolution mass spectra (HRMS) were obtained on a Q-TOF Ultima ESI instrument (micrOTOF-Q II, Bruker Daltonics, Leipzig, Germany). Analysis by thin layer chromatography (TLC) was performed on silica gel plates (Merck, Billerica, MA, USA). Automated column chromatography was conducted over silica gel using a Companion Rf 200 automated chromatography system (Teledyne ISCO, Lincoln, NE, USA).

\section{General synthetic procedures}

Method A: general procedure for the preparation of esters (1b, 2b, 3b, 8a-t, 9a-t and 10a-t) from corresponding acids. ${ }^{15}$ To a solution of the corresponding acid (1 equiv.) in corresponding. alcohol $\left(2 \mathrm{~mL} \mathrm{mmol}^{-1}\right)$ was added concentrated sulfuric acid $\left(25 \mu \mathrm{L} \mathrm{mmol}^{-1}\right)$. The reaction mixture was refluxed overnight, then cooled, concentrated, diluted with sat. $\mathrm{NaHCO}_{3}$ solution, extracted with DCM, dried over $\mathrm{Na}_{2} \mathrm{SO}_{4}$ and concentrated in vacuum. The residue was purified by flash column chromatography on silica with an elution of hexanes/EtOAc $4: 1$ to give the corresponding ester.

Method B: general procedure for the preparation of amides (1c, $2 \mathrm{c}$ and 3c) from corresponding acids. ${ }^{16}$ To a solution of the corresponding acid (1 equiv.) in anhydrous THF $\left(5 \mathrm{~mL} \mathrm{mmol}^{-1}\right)$ was added triethylamine (2 equiv.) under argon atmosphere, and cooled to $-15{ }^{\circ} \mathrm{C}$. Isobutylchloroformate (IBCF, 2 equiv.) was added dropwise at a rate so as to not exceed an internal temperature of $-10{ }^{\circ} \mathrm{C}$. After stirring for $1 \mathrm{~h}$ at $-15{ }^{\circ} \mathrm{C}$, ammonia gas was slowly bubbled into the reaction mixture. During the bubbling, the reaction temperature rose to $0{ }^{\circ} \mathrm{C}$ and 
kept the reaction temperature at $0{ }^{\circ} \mathrm{C}$ overnight. Then the reaction mixture was diluted with EtOAc $\left(10 \mathrm{~mL} \mathrm{mmol}^{-1}\right)$ and washed with $10 \%$ aqueous sodium chloride solution, followed by saturated brine. The organic layer was dried over $\mathrm{Na}_{2} \mathrm{SO}_{4}$. After filtration, the solvent was removed under reduced pressure to give the corresponding amide.

Method C: general procedure for the preparation of $\boldsymbol{E}-\boldsymbol{\gamma}$-oxo$\alpha, \beta$-alkenyl acids (7a-t). ${ }^{17}$ To a solution of glyoxylic acid (5, 1 equiv.) in acetic acid ( $\left.2 \mathrm{~mL} \mathrm{mmol}^{-1}\right)$ was added corresponding methyl ketone ( 1 equiv.). The resulting mixture was refluxed for overnight and monitored by TLC using ethyl acetate/petroleum ether $(2: 1)$ as a solvent system. After cooling, the solvent was evaporated. The residue was washed with ice-cold water by decantation or on a filter. The crude product was dried in air at $40{ }^{\circ} \mathrm{C}$ and recrystallized from ethyl acetate or purified by column chromatography over silica gel with elution of a mixture of petroleum ether and ethyl acetate $(2: 1)$ to give the corresponding acid. For the synthesis of compound $7 \mathbf{s}$, catalytic amount of morpholine hydrochloride was used as a catalyst without acetic acid as a solvent at $120{ }^{\circ} \mathrm{C}$ for overnight.

Method D: general procedure for the preparation of $E-\gamma-$ oxo$\boldsymbol{\alpha}, \boldsymbol{\beta}$-alkenyl acids $(\mathbf{1 1 a}-\mathbf{t})$. To a solution of $7 \mathbf{a}-\mathbf{t}$ (1 equiv.) in anhydrous dichloromethane $\left(10 \mathrm{~mL} \mathrm{mmol}^{-1}\right)$ was added triethylamine (TEA, 2 equiv.), followed by the addition dropwise of isobutylchloroformate (IBCF, 1.5 equiv.) at $-15{ }^{\circ} \mathrm{C}$ in nitrogen atmosphere. After the addition done, the resulting mixture was stirred at $-15{ }^{\circ} \mathrm{C}$ for further $8 \mathrm{~h}$. $\mathrm{N}$-Boc-ethanolamine $(0.8$ equiv.) was added and the reaction mixture was stirred for overnight and allowed to warm to room temperature. The reaction mixture was washed sequentially by saturated aqueous ammonium chloride and saturated brine, dried over $\mathrm{Na}_{2} \mathrm{SO}_{4}$. After filtration, the solvent was removed under reduced pressure. The residue was purified by flash column chromatography on silica with an elution of hexanes/EtOAc $4: 1$ to give the corresponding ester.

(E)-Methyl 3-(4-methoxyphenyl) acrylate $(\mathbf{1 b})$. Pale yellow solid (92\%) yield, mp: 89.0-90.5 ${ }^{\circ} \mathrm{C} .{ }^{1} \mathrm{H}$ NMR (400 MHz, $\left.\mathrm{CDCl}_{3}\right) \delta 7.65$ (d, $J=15.6 \mathrm{~Hz}, 1 \mathrm{H}), 7.49-7.47(\mathrm{~m}, 2 \mathrm{H}), 6.92-6.89(\mathrm{~m}, 2 \mathrm{H}), 6.31$ (d, $J=15.6 \mathrm{~Hz}, 1 \mathrm{H}), 3.84(\mathrm{~s}, 3 \mathrm{H}), 3.79$ (s, 3H); HRMS (ESI) $m / z$ calcd for $\mathrm{C}_{11} \mathrm{H}_{12} \mathrm{O}_{3} \mathrm{Na}[\mathrm{M}+\mathrm{Na}] 215.0684$, found 215.0672.

(E)-3-(4-Methoxyphenyl) acrylamide (1c). Yellow solid (75\%), mp: $188.2-189.7{ }^{\circ} \mathrm{C} .{ }^{1} \mathrm{H}$ NMR $\left(500 \mathrm{MHz}, \mathrm{CDCl}_{3}\right) \delta 7.61$ (d, $J=$ $15.5 \mathrm{~Hz}, 1 \mathrm{H}), 7.48-7.46(\mathrm{~m}, 2 \mathrm{H}), 6.91-6.89(\mathrm{~m}, 2 \mathrm{H}), 6.33(\mathrm{~d}, J=$ $15.5 \mathrm{~Hz}, 1 \mathrm{H}), 5.54(\mathrm{~m}, 2 \mathrm{H}), 3.84(\mathrm{~s}, 3 \mathrm{H})$; HRMS (ESI) $\mathrm{m} / \mathrm{z}$ calcd for $\mathrm{C}_{10} \mathrm{H}_{11} \mathrm{NO}_{2} \mathrm{Na}[\mathrm{M}+\mathrm{Na}] 200.0687$, found 200.0684 .

4-(4-Methoxyphenyl)-4-oxobutanoic acid (2a). ${ }^{14}$ To a mixture of anisole (10.8 g, $100 \mathrm{mmol}$ ) and anhydrous aluminum chloride $(32.0 \mathrm{~g}, 240 \mathrm{mmol})$ in nitrobenzene $(150 \mathrm{~mL})$ at $0-5{ }^{\circ} \mathrm{C}$ was added dropwise a solution of succinic anhydride (12.0 g, 120 $\mathrm{mmol})$ in nitrobenzene $(150 \mathrm{~mL})$ and maintained the same temperature. After addition completed, the reaction mixture was stirred at room temperature for $1 \mathrm{~h}$ and then heated up to $60{ }^{\circ} \mathrm{C}$ for a further $3 \mathrm{~h}$. The reaction mixture was cooled, poured into ice-cold water $(800 \mathrm{~mL})$ and the resulting precipitate was filtered, washed with water and hexane to give a crude, which was crystallized from methanol/ethyl acetate $(1: 9)$ to give a colorless crystal of $2 \mathrm{a}(16.7 \mathrm{~g}, 80 \%)$, mp: $150-151{ }^{\circ} \mathrm{C} .{ }^{1} \mathrm{H}$ NMR $\left(400 \mathrm{MHz}, \mathrm{CDCl}_{3}\right) \delta$ 7.98-7.96 (m, 2H), 6.96-6.94 (m, 2H), 3.88 $(\mathrm{s}, 3 \mathrm{H}), 3.29(\mathrm{t}, J=6.8 \mathrm{~Hz}, 2 \mathrm{H}), 2.81(\mathrm{t}, J=6.8 \mathrm{~Hz}, 2 \mathrm{H})$; HRMS (ESI) $\mathrm{m} / z$ calcd for $\mathrm{C}_{11} \mathrm{H}_{12} \mathrm{O}_{4} \mathrm{Na}[\mathrm{M}+\mathrm{Na}] 231.0633$, found 231.0625 .

Methyl 4-(4-methoxyphenyl)-4-oxobutanoate (2b). White solid (95\%), mp: 48.1-49.4 ${ }^{\circ} \mathrm{C} .{ }^{1} \mathrm{H}$ NMR (400 MHz, $\left.\mathrm{CDCl}_{3}\right) \delta 7.98-7.96$ $(\mathrm{m}, 2 \mathrm{H}), 6.95-6.93(\mathrm{~m}, 2 \mathrm{H}), 3.87(\mathrm{~s}, 3 \mathrm{H}), 3.71(\mathrm{~s}, 3 \mathrm{H}), 3.28(\mathrm{t}, J=$ $6.8 \mathrm{~Hz}, 2 \mathrm{H}$ ), 2.75 (t, $J=6.8 \mathrm{~Hz}, 2 \mathrm{H}$ ); HRMS (ESI) $\mathrm{m} / z$ calcd for $\mathrm{C}_{11} \mathrm{H}_{14} \mathrm{O}_{4} \mathrm{Na}[\mathrm{M}+\mathrm{Na}] 245.0790$, found 245.0779.

4-(4-Methoxyphenyl)-4-oxobutanamide (2c). White solid (80\%), mp: 134.6-136.3 ${ }^{\circ} \mathrm{C} .{ }^{1} \mathrm{H}$ NMR (500 MHz, DMSO- $\left.d_{6}\right) \delta 7.94-7.93$ $(\mathrm{m}, 2 \mathrm{H}), 7.30(\mathrm{~s}, 1 \mathrm{H}), 7.04-7.02(\mathrm{~m}, 2 \mathrm{H}), 6.72(\mathrm{~s}, 1 \mathrm{H}), 3.83(\mathrm{~s}, 3 \mathrm{H})$, $3.14(\mathrm{t}, J=6.5 \mathrm{~Hz}, 2 \mathrm{H}), 2.41(\mathrm{t}, J=6.5 \mathrm{~Hz}, 2 \mathrm{H}) ;{ }^{13} \mathrm{C}$ NMR (125 MHz, DMSO- $\left.d_{6}\right) \delta 197.26,173.36,163.00,130.10,129.61,113.83$, $55.50,32.85$, 28.97; HRMS (ESI) $m / z$ calcd for $\mathrm{C}_{11} \mathrm{H}_{14} \mathrm{NO}_{3} \mathrm{Na}[\mathrm{M}+$ $\mathrm{Na}$ ] 230.0793, found 230.0779.

4-(4-Methoxyphenyl) butanoic acid (3a). A mixture of $2 \mathrm{a}(3.12 \mathrm{~g}$, $15.00 \mathrm{mmol})$ and triethylsilane $(10.5 \mathrm{~g}, 90.0 \mathrm{mmol})$ in trifluoroacetic acid $(20 \mathrm{~mL})$ was heated to $50{ }^{\circ} \mathrm{C}$ under argon atmosphere for $5 \mathrm{~h}$. After cooling, the solvent was evaporated in vacuum, then the reaction mass was diluted with water $(100 \mathrm{~mL})$ and EtOAc $(100 \mathrm{~mL})$ and stirred for $5 \mathrm{~min}$. The aqueous layer was extracted with EtOAc $(100 \mathrm{~mL} \times 2)$ and the combined organic extracts were washed with saturated brine and dried over $\mathrm{Na}_{2} \mathrm{SO}_{4}$. After filtration, the solvent was removed under reduced pressure and then co-evaporated with hexanes $(50 \mathrm{~mL})$. The residue was treated by flash column chromatography on silica with a elution of hexanes/EtOAc $1: 1$ to give $3 a$ as a colorless solid (2.10 g, 72\%): mp 62.5-63.5 ${ }^{\circ} \mathrm{C} ;{ }^{1} \mathrm{H}$ NMR (400 $\left.\mathrm{MHz}, \mathrm{CDCl}_{3}\right) \delta$ 7.11-7.09 (m, 2H), 6.84-6.82 (m, 2H), $3.79(\mathrm{~s}$, $3 \mathrm{H}), 2.62(\mathrm{t}, J=7.6 \mathrm{~Hz}, 2 \mathrm{H}), 2.36(\mathrm{t}, J=7.6 \mathrm{~Hz}, 2 \mathrm{H}), 1.97-1.92(\mathrm{~m}$, $2 \mathrm{H}$ ); HRMS (ESI) $m / z$ calcd for $\mathrm{C}_{11} \mathrm{H}_{14} \mathrm{O}_{3} \mathrm{Na}[\mathrm{M}+\mathrm{Na}]$ 217.0841, found 217.0830 .

Methyl 4-(4-methoxyphenyl) butanoate (3b). Pale yellow oil (94\%). ${ }^{1} \mathrm{H}$ NMR (400 MHz, $\left.\mathrm{CDCl}_{3}\right) \delta$ 7.10-7.08 (m, 2H), 6.84-6.82 $(\mathrm{m}, 2 \mathrm{H}), 3.78(\mathrm{~s}, 3 \mathrm{H}), 3.66(\mathrm{~s}, 3 \mathrm{H}), 2.59(\mathrm{t}, J=7.6 \mathrm{~Hz}, 2 \mathrm{H}), 2.32(\mathrm{t}$, $J=7.6 \mathrm{~Hz}, 2 \mathrm{H}), 1.96-1.91(\mathrm{~m}, 2 \mathrm{H})$; HRMS (ESI) $\mathrm{m} / \mathrm{z}$ calcd for $\mathrm{C}_{12} \mathrm{H}_{16} \mathrm{O}_{3} \mathrm{Na}[\mathrm{M}+\mathrm{Na}] 231.0997$, found 231.0983.

4-(4-Methoxyphenyl) butanamide (3c). White solid (85\%), mp: 121.6-123.3 ${ }^{\circ} \mathrm{C} .{ }^{1} \mathrm{H}$ NMR (500 MHz, $\left.\mathrm{CDCl}_{3}\right): \delta 7.10-7.08(\mathrm{~m}, 2 \mathrm{H})$, 6.83-6.82 (m, 2H), $5.57(\mathrm{~s}, 1 \mathrm{H}), 5.41(\mathrm{~s}, 1 \mathrm{H}), 3.78(\mathrm{~s}, 3 \mathrm{H}), 2.61(\mathrm{t}, J$ $=7.5 \mathrm{~Hz}, 2 \mathrm{H}), 2.32(\mathrm{t}, J=7.5 \mathrm{~Hz}, 2 \mathrm{H}), 1.96-1.91(\mathrm{~m}, 2 \mathrm{H}) ;{ }^{13} \mathrm{C}$ NMR (125 MHz, DMSO- $\left.d_{6}\right) \delta 174.04,157.39,133.67,129.21$, 113.68, 54.95, 34.49, 33.79, 27.11; HRMS (ESI) $\mathrm{m} / \mathrm{z}$ calcd for $\mathrm{C}_{11} \mathrm{H}_{15} \mathrm{NO}_{2} \mathrm{Na}[\mathrm{M}+\mathrm{Na}] 216.1000$, found 216.0987.

(Z)-Methyl 4-(4-methoxyphenyl)-4-oxobut-2-enoate (4) and (E)methyl 4-(4-methoxyphenyl)-4-oxobut-2-enoate ( 8 a or $\mathbf{Y H - 8 ) . ~ T o ~}$ a solution of $7.40 \mathrm{~g}$ of glyoxylic acid $(5.56 \mathrm{~mL}, 100 \mathrm{mmol})$ in acetic acid $(100 \mathrm{~mL})$ was added $5(15.0 \mathrm{~g}, 100 \mathrm{mmol})$, and the resulting mixture was stirred at $120^{\circ} \mathrm{C}$ overnight. After cooling, the solvent was evaporated. The residue was washed with icecold water $(50 \mathrm{~mL})$ by decantation or on a filter. The crude product was dried in air at $50{ }^{\circ} \mathrm{C}$ and recrystallized from ethyl acetate to give 7a ((E)-4-(4-methoxyphenyl)-4-oxobut-2-enoic acid) as a pale yellow powder (10.7 g, 52\%), mp: 139.2$140.8{ }^{\circ} \mathrm{C} .{ }^{1} \mathrm{H}$ NMR $\left(400 \mathrm{MHz}, \mathrm{CDCl}_{3}\right) \delta 8.03-7.97$ (m, 3H), 7.01$6.98(\mathrm{~m}, 2 \mathrm{H}), 6.89$ (d, $J=15.6 \mathrm{~Hz}, 1 \mathrm{H}), 3.90(\mathrm{~s}, 3 \mathrm{H})$; HRMS (ESI) 
$m / z$ calcd for $\mathrm{C}_{11} \mathrm{H}_{10} \mathrm{O}_{4} \mathrm{Na}[\mathrm{M}+\mathrm{H}] 207.0657$, found 207.0649 [M $+\mathrm{H}]$. To a stirring solution of $7 \mathbf{a}(1.03 \mathrm{~g}, 5.00 \mathrm{~mol})$ in methanol $(10 \mathrm{~mL})$ was added concentrated sulfuric acid $(125 \mu \mathrm{L})$. The reaction mixture was refluxed overnight, then cooled, concentrated, diluted with sat. $\mathrm{NaHCO}_{3}$ solution, extracted with DCM, dried over $\mathrm{Na}_{2} \mathrm{SO}_{4}$ and concentrated in vacuum. The residue was purified by flash column chromatography on silica with an elution of hexanes/EtOAc $4: 1$ to give $4 \mathbf{a}$ and 8a, respectively. 4a as a yellow oil $(0.53 \mathrm{~g}, 48 \%) ;{ }^{1} \mathrm{H}$ NMR $\left(400 \mathrm{MHz}^{\mathrm{CDCl}} \mathrm{CDC}_{3}\right) \delta .92-$ $7.90(\mathrm{~m}, 2 \mathrm{H}), 6.96-6.94(\mathrm{~m}, 2 \mathrm{H}), 6.89(\mathrm{~d}, J=12.0 \mathrm{~Hz}, 1 \mathrm{H}), 6.26(\mathrm{~d}$, $J=12.0 \mathrm{~Hz}, 1 \mathrm{H}), 3.87(\mathrm{~s}, 3 \mathrm{H}), 3.61(\mathrm{~s}, 3 \mathrm{H}) ; 8 \mathrm{a}$ as a yellow solid (0.53 g, 48\%), mp: 72.9-73.7 ${ }^{\circ} \mathrm{C} ;{ }^{1} \mathrm{H} \mathrm{NMR} \mathrm{(400} \mathrm{MHz,} \mathrm{CDCl}_{3}$ ) $\delta 8.02-8.00(\mathrm{~m}, 2 \mathrm{H}), 7.93(\mathrm{~d}, J=15.6 \mathrm{~Hz}, 1 \mathrm{H}), 6.99-6.97(\mathrm{~m}, 2 \mathrm{H})$, $6.88(\mathrm{~d}, J=15.6 \mathrm{~Hz}, 1 \mathrm{H}), 3.84(\mathrm{~s}, 3 \mathrm{H}), 3.89$ (s, 3H); HRMS (ESI) $m / z$ calcd for $\mathrm{C}_{12} \mathrm{H}_{12} \mathrm{O}_{4} \mathrm{Na}[\mathrm{M}+\mathrm{Na}] 243.0633$, found 243.0627 $[\mathrm{M}+\mathrm{Na}]$.

(E)-4-Oxo-4-phenylbut-2-enoic acid (7b). Yellow solid (74\%), mp: 88.6-90.2 ${ }^{\circ} \mathrm{C} .{ }^{1} \mathrm{H}$ NMR (400 MHz, DMSO- $\left.d_{6}\right) \delta 13.17(\mathrm{~s}, 1 \mathrm{H})$, 8.07-8.01 (m, 2H), 7.89 (d, $J=15.6 \mathrm{~Hz}, 1 \mathrm{H}), 7.74-7.70(\mathrm{~m}, 1 \mathrm{H})$, 7.61-7.57 (m, 2H), 6.69 (d, $J=15.6 \mathrm{~Hz}, 1 \mathrm{H})$; HRMS (ESI) $m / z$ calcd for $\mathrm{C}_{10} \mathrm{H}_{7} \mathrm{O}_{3}[\mathrm{M}-\mathrm{H}]$ 175.0395, found $175.0393[\mathrm{M}-\mathrm{H}]$.

(E)-4-Oxo-4-(p-tolyl)but-2-enoic acid (7c). Yellow solid (76\%), mp: $141.4-142.7{ }^{\circ} \mathrm{C} .{ }^{1} \mathrm{H}$ NMR (400 MHz, DMSO- $\left.d_{6}\right) \delta 13.15$ (s, 1H), 7.96-7.94 (m, 2H), 7.88 (d, $J=15.6 \mathrm{~Hz}, 1 \mathrm{H}), 7.40-7.38(\mathrm{~m}$, $2 \mathrm{H}), 6.67(\mathrm{~d}, J=15.6 \mathrm{~Hz}, 1 \mathrm{H}), 2.41(\mathrm{~s}, 3 \mathrm{H})$; HRMS (ESI) $m / z$ calcd for $\mathrm{C}_{11} \mathrm{H}_{9} \mathrm{O}_{3}[\mathrm{M}-\mathrm{H}]$ 189.0552, found 189.0559 [M $\left.-\mathrm{H}\right]$.

(E)-4-(4-Ethoxyphenyl)-4-oxobut-2-enoic acid (7d). Yellow solid (72\%), mp: $150.3-151.7{ }^{\circ} \mathrm{C} .{ }^{1} \mathrm{H}$ NMR (400 MHz, DMSO- $d_{6}$ ) $\delta 13.09(\mathrm{~s}, 1 \mathrm{H}), 8.04-8.01(\mathrm{~m}, 2 \mathrm{H}), 7.89(\mathrm{~d}, J=15.6 \mathrm{~Hz}, 1 \mathrm{H}), 7.09-$ $7.06(\mathrm{~m}, 2 \mathrm{H}), 6.66(\mathrm{~d}, J=15.6 \mathrm{~Hz}, 1 \mathrm{H}), 4.15(\mathrm{q}, J=7.2 \mathrm{~Hz}, 2 \mathrm{H})$, $1.36\left(\mathrm{t}, J=7.2 \mathrm{~Hz}, 3 \mathrm{H}\right.$ ); HRMS (ESI) $m / z$ calcd for $\mathrm{C}_{12} \mathrm{H}_{11} \mathrm{O}_{4}[\mathrm{M}-$ $\mathrm{H}]$ 219.0657, found 219.0651 [M - H].

(E)-4-(2-Methoxyphenyl)-4-oxobut-2-enoic acid (7e). Yellow solid (73\%), mp: $151.8-153.0{ }^{\circ} \mathrm{C} .{ }^{1} \mathrm{H}$ NMR (500 MHz, DMSO- $d_{6}$ ) $\delta 13.05(\mathrm{~s}, 1 \mathrm{H}), 7.66-7.52(\mathrm{~m}, 3 \mathrm{H}), 7.23-7.21$ (m, 1H), 7.12-7.05 (m, 1H), 6.51 (d, $J=15.5 \mathrm{~Hz}, 1 \mathrm{H}), 3.88$ (s, 3H); HRMS (ESI) $m / z$ calcd for $\mathrm{C}_{11} \mathrm{H}_{10} \mathrm{O}_{4} \mathrm{Na}[\mathrm{M}+\mathrm{Na}] 229.0477$, found $229.0467[\mathrm{M}+$ $\mathrm{Na}$.

(E)-4-(3-Methoxyphenyl)-4-oxobut-2-enoic acid (7f). Yellow solid (71\%), mp: $114.5-115.8{ }^{\circ} \mathrm{C} .{ }^{1} \mathrm{H}$ NMR (500 MHz, DMSO- $\left.d_{6}\right)$ $\delta 13.17(\mathrm{~s}, 1 \mathrm{H}), 7.86(\mathrm{~d}, J=15.5 \mathrm{~Hz}, 1 \mathrm{H}), 7.66-7.61(\mathrm{~m}, 1 \mathrm{H}), 7.53-$ $7.46(\mathrm{~m}, 2 \mathrm{H}), 7.30-7.27(\mathrm{~m}, 1 \mathrm{H}), 6.68(\mathrm{~d}, J=15.5 \mathrm{~Hz}, 1 \mathrm{H}), 3.84(\mathrm{~s}$, $3 \mathrm{H}$ ); HRMS (ESI) $m / z$ calcd for $\mathrm{C}_{11} \mathrm{H}_{10} \mathrm{O}_{4} \mathrm{Na}[\mathrm{M}+\mathrm{Na}] 229.0477$, found 229.0466 [M $+\mathrm{Na}]$.

(E)-4-(2,5-Dimethoxyphenyl)-4-oxobut-2-enoic acid (7g). Yellow solid (73\%). Mp: $152.4-153.7{ }^{\circ} \mathrm{C} .{ }^{1} \mathrm{H}$ NMR (500 MHz, DMSO- $d_{6}$ ) $\delta 13.06(\mathrm{~s}, 1 \mathrm{H}), 7.60(\mathrm{~d}, J=15.5 \mathrm{~Hz}, 1 \mathrm{H}), 7.23-7.15(\mathrm{~m}, 2 \mathrm{H}), 7.09-$ $7.08(\mathrm{~m}, 1 \mathrm{H}), 6.52(\mathrm{~d}, J=15.5 \mathrm{~Hz}, 1 \mathrm{H}), 3.83(\mathrm{~s}, 3 \mathrm{H}), 3.75(\mathrm{~s}, 3 \mathrm{H})$; HRMS (ESI) $m / z$ calcd for $\mathrm{C}_{12} \mathrm{H}_{11} \mathrm{O}_{5}[\mathrm{M}-\mathrm{H}] 235.0606$, found $235.0603[\mathrm{M}-\mathrm{H}]$.

(E)-4-(3,4-Dimethoxyphenyl)-4-oxobut-2-enoic acid (7h). Yellow solid (75\%). Mp: 183.1-184.3 ${ }^{\circ} \mathrm{C} .{ }^{1} \mathrm{H}$ NMR (400 MHz, DMSO- $d_{6}$ ) $\delta 13.11(\mathrm{~s}, 1 \mathrm{H}), 7.93(\mathrm{~d}, J=15.6 \mathrm{~Hz}, 1 \mathrm{H}), 7.77-7.75(\mathrm{~m}, 1 \mathrm{H}), 7.51-$ $7.50(\mathrm{~m}, 1 \mathrm{H}), 7.12-7.10(\mathrm{~m}, 1 \mathrm{H}), 6.66(\mathrm{~d}, J=15.6 \mathrm{~Hz}, 1 \mathrm{H}), 3.87(\mathrm{~s}$, $3 \mathrm{H}), 3.84\left(\mathrm{~s}, 3 \mathrm{H}\right.$ ); HRMS (ESI) $m / z$ calcd for $\mathrm{C}_{12} \mathrm{H}_{11} \mathrm{O}_{5}[\mathrm{M}-\mathrm{H}]$ 235.0606, found 235.0610 [M $-\mathrm{H}]$.
(E)-4-(Benzo[d][1,3]dioxol-5-yl)-4-oxobut-2-enoic acid (7i). Yellow solid (74\%). Mp: 204.0-205.5 ${ }^{\circ} \mathrm{C}$. ${ }^{1} \mathrm{H}$ NMR $(400 \mathrm{MHz}$, DMSO- $\left.d_{6}\right) \delta 13.12(\mathrm{~s}, 1 \mathrm{H}), 7.86(\mathrm{~d}, J=15.6 \mathrm{~Hz}, 1 \mathrm{H}), 7.74-7.72(\mathrm{~m}$, 1H), 7.50-7.49 (m, 1H), 7.09-7.07 (m, 1H), 6.65 (d, $J=15.6 \mathrm{~Hz}$, 1H), 6.18 (s, 2H); MS-ESI ( $\mathrm{m} / \mathrm{z}): 219.06[\mathrm{M}-\mathrm{H}]$.

(E)-4-(2,3-Dihydrobenzofuran-5-yl)-4-oxobut-2-enoic acid (7j). Yellow solid (73\%). Mp: 168.6-170.2 ${ }^{\circ} \mathrm{C}$. ${ }^{1} \mathrm{H}$ NMR $(400 \mathrm{MHz}$, $\left.\mathrm{CD}_{3} \mathrm{OD}\right) \delta$ 7.96-7.89 (m, 3H), 6.89-6.84 (m, 1H), $6.74(\mathrm{~d}, J=$ $15.6 \mathrm{~Hz}, 1 \mathrm{H}), 4.68(\mathrm{t}, J=8.8 \mathrm{~Hz}, 2 \mathrm{H}), 3.30(\mathrm{t}, J=8.8 \mathrm{~Hz}, 2 \mathrm{H})$; HRMS (ESI) $m / z$ calcd for $\mathrm{C}_{12} \mathrm{H}_{10} \mathrm{O}_{4} \mathrm{Na}[\mathrm{M}+\mathrm{Na}] 241.0477$, found $241.0480[\mathrm{M}+\mathrm{Na}]$.

(E)-4-([1,1'-Biphenyl]-4-yl)-4-oxobut-2-enoic acid (7k). Yellow solid (65\%). Mp: $226.3-227.4{ }^{\circ} \mathrm{C} .{ }^{1} \mathrm{H}$ NMR (400 MHz, DMSO- $d_{6}$ ) $\delta 13.15(\mathrm{~s}, 1 \mathrm{H}), 8.14-8.12(\mathrm{~m}, 2 \mathrm{H}), 7.93(\mathrm{~d}, J=15.6 \mathrm{~Hz}, 1 \mathrm{H}), 7.90-$ $7.88(\mathrm{~m}, 2 \mathrm{H}), 7.79-7.77(\mathrm{~m}, 2 \mathrm{H}), 7.54-7.50(\mathrm{~m}, 2 \mathrm{H}), 7.46-7.43$ $(\mathrm{m}, 1 \mathrm{H}), 6.76(\mathrm{~d}, J=15.6 \mathrm{~Hz}, 1 \mathrm{H})$; HRMS (ESI) $\mathrm{m} / \mathrm{z}$ calcd for $\mathrm{C}_{16} \mathrm{H}_{10} \mathrm{O}_{3}[\mathrm{M}-\mathrm{H}]$ 251.0708, found 251.0714 [M - H].

(E)-4-Oxo-4-(4-phenoxyphenyl)but-2-enoic acid (7l). Yellow solid (50\%). Mp: $123.2-125.6{ }^{\circ} \mathrm{C} .{ }^{1} \mathrm{H}$ NMR (400 MHz, DMSO- $d_{6}$ ) $\delta 13.15(\mathrm{~s}, 1 \mathrm{H}), 8.09-8.07(\mathrm{~m}, 2 \mathrm{H}), 7.87(\mathrm{~d}, J=15.6 \mathrm{~Hz}, 1 \mathrm{H}), 7.50-$ $7.46(\mathrm{~m}, 2 \mathrm{H}), 7.30-7.26(\mathrm{~m}, 1 \mathrm{H}), 7.17-7.15(\mathrm{~m}, 2 \mathrm{H}), 7.09-7.07$ $(\mathrm{m}, 2 \mathrm{H}), 6.67$ (d, $J=15.6 \mathrm{~Hz}, 1 \mathrm{H})$; HRMS (ESI) $\mathrm{m} / \mathrm{z}$ calcd for $\mathrm{C}_{16} \mathrm{H}_{11} \mathrm{O}_{4}[\mathrm{M}-\mathrm{H}]$ 267.0657, found 267.0658 [M - H].

(E)-4-(Naphthalen-1-yl)-4-oxobut-2-enoic acid (7m). Yellow solid (55\%). Mp: $150.1-151.7{ }^{\circ} \mathrm{C} .{ }^{1} \mathrm{H}$ NMR (400 MHz, DMSO- $d_{6}$ ) $\delta 13.21(\mathrm{~s}, 1 \mathrm{H}), 8.47-8.45(\mathrm{~m}, 1 \mathrm{H}), 8.23-8.21(\mathrm{~m}, 1 \mathrm{H}), 8.08-8.04$ (m, 2H), 7.70-7.60 (m, 4H), $6.61(\mathrm{~d}, J=15.6 \mathrm{~Hz}, 1 \mathrm{H})$; HRMS (ESI) $m / z$ calcd for $\mathrm{C}_{14} \mathrm{H}_{10} \mathrm{O}_{3} \mathrm{Na}[\mathrm{M}+\mathrm{Na}] 249.0528$, found $249.0515[\mathrm{M}$ $+\mathrm{Na}]$.

(E)-4-(2,4-Dichlorophenyl)-4-oxobut-2-enoic acid (7n). Yellow solid (58\%). Mp: $201.3-202.8{ }^{\circ} \mathrm{C} .{ }^{1} \mathrm{H}$ NMR (400 MHz, DMSO- $d_{6}$ ) $\delta 13.30(\mathrm{~s}, 1 \mathrm{H}), 7.81-7.80(\mathrm{~m}, 1 \mathrm{H}), 7.70-7.68(\mathrm{~m}, 1 \mathrm{H}), 7.61-7.58$ $(\mathrm{m}, 1 \mathrm{H}), 7.32(\mathrm{~d}, J=16.0 \mathrm{~Hz}, 1 \mathrm{H}), 6.50(\mathrm{~d}, J=16.0 \mathrm{~Hz}, 1 \mathrm{H})$; HRMS (ESI) $m / z$ calcd for $\mathrm{C}_{10} \mathrm{H}_{6} \mathrm{Cl}_{2} \mathrm{O}_{3}[\mathrm{M}-\mathrm{H}] 242.9616$, found $242.9612[\mathrm{M}-\mathrm{H}]$.

(E)-4-(4-Nitrophenyl)-4-oxobut-2-enoic acid (7o). Yellow solid (60\%). Mp: $172.8-174.4{ }^{\circ} \mathrm{C} .{ }^{1} \mathrm{H}$ NMR (400 MHz, DMSO- $\left.d_{6}\right)$ $\delta 13.26(\mathrm{~s}, 1 \mathrm{H}), 8.37-8.34(\mathrm{~m}, 2 \mathrm{H}), 8.25-8.23(\mathrm{~m}, 2 \mathrm{H}), 7.85(\mathrm{~d}, J=$ $15.6 \mathrm{~Hz}, 1 \mathrm{H}), 6.71(\mathrm{~d}, J=15.6 \mathrm{~Hz}, 1 \mathrm{H})$; HRMS (ESI) $\mathrm{m} / \mathrm{z}$ calcd for $\mathrm{C}_{10} \mathrm{H}_{6} \mathrm{NO}_{5}[\mathrm{M}-\mathrm{H}] 220.0246$, found $220.0261[\mathrm{M}-\mathrm{H}]$.

(E)-4-(4-Bromophenyl)-4-oxobut-2-enoic acid (7p). Yellow solid (64\%). Mp: $161.1-163.4{ }^{\circ} \mathrm{C} .{ }^{1} \mathrm{H}$ NMR (400 MHz, DMSO- $\left.d_{6}\right)$ $\delta 13.18(\mathrm{~s}, 1 \mathrm{H}), 6.97(\mathrm{~d}, J=15.6 \mathrm{~Hz}, 1 \mathrm{H}), 7.84(\mathrm{~d}, J=15.6 \mathrm{~Hz}, 1 \mathrm{H})$, 7.97-7.95 (m, 2H), 7.79-7.77 (m, 2H); HRMS (ESI) $\mathrm{m} / \mathrm{z}$ calcd for $\mathrm{C}_{10} \mathrm{H}_{6} \mathrm{BrO}_{3}[\mathrm{M}-\mathrm{H}]$ 253.9500, found 252.9489 [M $\left.-\mathrm{H}\right]$.

(E)-4-(Furan-2-yl)-4-oxobut-2-enoic acid (7q). Brown solid (64\%). Mp: $158.9-160.5{ }^{\circ} \mathrm{C} .{ }^{1} \mathrm{H}$ NMR (400 MHz, DMSO- $\left.d_{6}\right)$ $\delta 13.18(\mathrm{~s}, 1 \mathrm{H}), 8.14(\mathrm{~s}, 1 \mathrm{H}), 7.83-7.82(\mathrm{~m}, 1 \mathrm{H}), 7.71(\mathrm{~d}, J=$ $15.6 \mathrm{~Hz}, 1 \mathrm{H}), 6.85-6.78(\mathrm{~m}, 1 \mathrm{H}), 6.74$ (d, $J=15.6 \mathrm{~Hz}, 1 \mathrm{H})$; HRMS (ESI) $\mathrm{m} / z$ calcd for $\mathrm{C}_{8} \mathrm{H}_{5} \mathrm{O}_{4}[\mathrm{M}-\mathrm{H}] 165.0188$, found $165.0193[\mathrm{M}$ $-\mathrm{H}]$.

(E)-4-Oxohex-2-enoic acid (7r). White solid (54\%). Mp: 123.5$125.7^{\circ} \mathrm{C} .{ }^{1} \mathrm{H}$ NMR $\left(400 \mathrm{MHz}, \mathrm{DMSO}-d_{6}\right) \delta 13.13(\mathrm{~s}, 1 \mathrm{H}), 6.80(\mathrm{~d}, J$ $=16.0 \mathrm{~Hz}, 1 \mathrm{H}), 6.66(\mathrm{~d}, J=16.0 \mathrm{~Hz}, 1 \mathrm{H}), 2.34(\mathrm{~s}, 3 \mathrm{H})$; HRMS (ESI) $m / z$ calcd for $\mathrm{C}_{5} \mathrm{H}_{5} \mathrm{O}_{3}[\mathrm{M}-\mathrm{H}] 113.0239$, found 113.0244 $[\mathrm{M}-\mathrm{H}]$. 
(E)-4-Cyclohexyl-4-oxobut-2-enoic acid (7s). White solid (60\%). Mp: 125.6-127.1 ${ }^{\circ} \mathrm{C} .{ }^{1} \mathrm{HNMR}\left(400 \mathrm{MHz}, \mathrm{DMSO}-d_{6}\right) \delta 13.08(\mathrm{~s}$, $1 \mathrm{H}), 7.04(\mathrm{~d}, J=16.0 \mathrm{~Hz}, 1 \mathrm{H}), 6.60$ (d, $J=16.0 \mathrm{~Hz}, 1 \mathrm{H}), 2.82-$ $2.75(\mathrm{~m}, 1 \mathrm{H}), 1.80-1.60(\mathrm{~m}, 5 \mathrm{H}), 1.37-1.12(\mathrm{~m}, 5 \mathrm{H})$; HRMS (ESI) $m / z$ calcd for $\mathrm{C}_{10} \mathrm{H}_{13} \mathrm{O}_{3}[\mathrm{M}-\mathrm{H}] 181.0865$, found $181.0868[\mathrm{M}-\mathrm{H}]$.

(E)-4-Cyclopropyl-4-oxobut-2-enoic acid (7t). White solid (65\%), mp: 95.55-96. ${ }^{\circ} \mathrm{C} .{ }^{1} \mathrm{H}$ NMR (400 MHz, DMSO- $\left.d_{6}\right) \delta 13.12(\mathrm{~s}, 1 \mathrm{H})$, $7.04(\mathrm{~d}, J=16.0 \mathrm{~Hz}, 1 \mathrm{H}), 6.70(\mathrm{~d}, J=16.0 \mathrm{~Hz}, 1 \mathrm{H}), 2.53-2.47(\mathrm{~m}$, 1H), 1.03-0.97 (m, 4H); MS-ESI $(\mathrm{m} / \mathrm{z}): 163.04$ [M $+\mathrm{Na}]$.

(E)-Methyl 4-oxo-4-phenylbut-2-enoate (8b). Yellow solid (45\%), mp: $36.4-37.5{ }^{\circ} \mathrm{C} .{ }^{1} \mathrm{H}$ NMR $\left(400 \mathrm{MHz}, \mathrm{CDCl}_{3}\right) \delta 8.03-7.98(\mathrm{~m}$, $2 \mathrm{H}), 7.93(\mathrm{~d}, J=15.6 \mathrm{~Hz}, 1 \mathrm{H}), 7.66-7.59(\mathrm{~m}, 1 \mathrm{H}), 7.54-7.50(\mathrm{~m}$, 2H), $6.90(\mathrm{~d}, J=15.6 \mathrm{~Hz}, 1 \mathrm{H}), 3.85(\mathrm{~s}, 3 \mathrm{H}) ;{ }^{13} \mathrm{C}$ NMR $(125 \mathrm{MHz}$, DMSO- $\left.d_{6}\right) \delta 189.23,165.38,136.89,136.01,134.10,131.21$, 129.05, 128.84, 52.23; HRMS (ESI) $m / z$ calcd for $\mathrm{C}_{11} \mathrm{H}_{10} \mathrm{O}_{3} \mathrm{Na}[\mathrm{M}$ $+\mathrm{Na}$ 213.0528, found $213.0538[\mathrm{M}+\mathrm{Na}]$.

(E)-Methyl 4-oxo-4-(p-tolyl) but-2-enoate (8c). Yellow solid (46\%), mp: $48.7-49.6{ }^{\circ} \mathrm{C} .{ }^{1} \mathrm{H}$ NMR $\left(400 \mathrm{MHz}, \mathrm{CDCl}_{3}\right) \delta 7.94-7.90$ $(\mathrm{m}, 3 \mathrm{H}), 7.32-7.30(\mathrm{~m}, 2 \mathrm{H}), 6.88(\mathrm{~d}, J=15.6 \mathrm{~Hz}, 1 \mathrm{H}), 3.85(\mathrm{~s}, 3 \mathrm{H})$, $2.44(\mathrm{~s}, 3 \mathrm{H}) ;{ }^{13} \mathrm{C}$ NMR $\left(125 \mathrm{MHz}, \mathrm{DMSO}-d_{6}\right) \delta 188.54,165.43$, 144.83, 136.93, 133.57, 130.94, 129.63, 128.99, 52.20, 21.25; HRMS (ESI) $m / z$ calcd for $\mathrm{C}_{12} \mathrm{H}_{12} \mathrm{O}_{3} \mathrm{Na}[\mathrm{M}+\mathrm{Na}] 227.0684$, found $227.0691[\mathrm{M}+\mathrm{Na}]$.

(E)-Methyl 4-(4-ethoxyphenyl)-4-oxobut-2-enoate (8d). Yellow solid (42\%), mp: 81.7-83.2 ${ }^{\circ} \mathrm{C}$. ${ }^{1} \mathrm{H}$ NMR (400 $\mathrm{MHz}, \mathrm{CDCl}_{3}$ ) $\delta 8.03-7.97(\mathrm{~m}, 2 \mathrm{H}), 7.94(\mathrm{~d}, J=15.6 \mathrm{~Hz}, 1 \mathrm{H}), 7.01-6.92(\mathrm{~m}, 2 \mathrm{H})$, $6.88(\mathrm{~d}, J=15.6 \mathrm{~Hz}, 1 \mathrm{H}), 4.13$ (q, $J=7.2 \mathrm{~Hz}, 2 \mathrm{H}), 3.85(\mathrm{~s}, 3 \mathrm{H})$, $1.46(\mathrm{t}, J=7.2 \mathrm{~Hz}, 3 \mathrm{H}) ;{ }^{13} \mathrm{C}$ NMR $\left(125 \mathrm{MHz}, \mathrm{DMSO}-d_{6}\right) \delta 187.12$, 165.51, 163.30, 137.03, 131.42, 130.53, 128.84, 114.72, 63.76, $52.19,14.45$; HRMS (ESI) $\mathrm{m} / z$ calcd for $\mathrm{C}_{13} \mathrm{H}_{14} \mathrm{O}_{4} \mathrm{Na}[\mathrm{M}+\mathrm{Na}]$ 257.0790, found $257.0778[\mathrm{M}+\mathrm{Na}]$.

(E)-Methyl 4-(2-methoxyphenyl)-4-oxobut-2-enoate (8e). Yellow solid (47\%), mp: 68.3-69.7 ${ }^{\circ} \mathrm{C} .{ }^{1} \mathrm{H}$ NMR (500 MHz, DMSO- $\left.d_{6}\right)$ $\delta 7.67(\mathrm{~d}, J=15.5 \mathrm{~Hz}, 1 \mathrm{H}), 7.65-7.56(\mathrm{~m}, 2 \mathrm{H}), 7.24-7.22(\mathrm{~m}, 1 \mathrm{H})$, 7.10-7.07 (m, 1H), 6.59 (d, J=15.5 Hz, 1H), $3.89(\mathrm{~s}, 3 \mathrm{H}), 3.76$ (s, $3 \mathrm{H}) ;{ }^{13} \mathrm{C}$ NMR (125 MHz, DMSO- $\left.d_{6}\right) \delta 190.57,165.62,158.68$, $140.77,134.81$, 130.14, 128.93, 126.80, 120.83, 112.69, 56.01, 52.19; HRMS (ESI) $m / z$ calcd for $\mathrm{C}_{12} \mathrm{H}_{12} \mathrm{O}_{4} \mathrm{Na}[\mathrm{M}+\mathrm{Na}] 243.0633$, found $243.0625[\mathrm{M}+\mathrm{Na}]$.

(E)-Methyl 4-(3-methoxyphenyl)-4-oxobut-2-enoate (8f). Yellow solid (42\%), mp: 58.4-60.0 ${ }^{\circ} \mathrm{C} .{ }^{1} \mathrm{H}$ NMR (500 MHz, DMSO- $\left.d_{6}\right)$ $\delta 7.95(\mathrm{~d}, J=15.5 \mathrm{~Hz}, 1 \mathrm{H}), 7.66-7.64(\mathrm{~m}, 1 \mathrm{H}), 7.55-7.47(\mathrm{~m}, 2 \mathrm{H})$, 7.30-7.28 (m, 1H), $6.75(\mathrm{~d}, J=15.5 \mathrm{~Hz}, 1 \mathrm{H}), 3.84(\mathrm{~s}, 3 \mathrm{H}), 3.79(\mathrm{~s}$, $3 \mathrm{H}) ;{ }^{13} \mathrm{C}$ NMR $\left(125 \mathrm{MHz}, \mathrm{DMSO}-d_{6}\right) \delta 188.95,165.38,159.62$, 137.41, 136.85, 131.28, 130.22, 121.53, 120.37, 112.82, 55.39, 52.21; HRMS (ESI) $m / z$ calcd for $\mathrm{C}_{12} \mathrm{H}_{12} \mathrm{O}_{4} \mathrm{Na}[\mathrm{M}+\mathrm{Na}] 243.0633$, found 243.0616 [M $+\mathrm{Na}]$.

(E)-Methyl 4-(2,5-dimethoxyphenyl)-4-oxobut-2-enoate (8g). Yellow solid (43\%). Mp: 74.4-75.7 ${ }^{\circ} \mathrm{C} .{ }^{1} \mathrm{H}$ NMR $(500 \mathrm{MHz}$, DMSO- $\left.d_{6}\right) \delta 7.68(\mathrm{~d}, J=15.5 \mathrm{~Hz}, 1 \mathrm{H}), 7.23-7.17(\mathrm{~m}, 2 \mathrm{H}), 7.11-$ $7.10(\mathrm{~m}, 1 \mathrm{H}), 6.59(\mathrm{~d}, J=15.5 \mathrm{~Hz}, 1 \mathrm{H}), 3.84(\mathrm{~s}, 3 \mathrm{H}), 3.76(\mathrm{~s}, 3 \mathrm{H})$, $3.75(\mathrm{~s}, 3 \mathrm{H}) ;{ }^{13} \mathrm{C}$ NMR $\left(125 \mathrm{MHz}, \mathrm{DMSO}-d_{6}\right) \delta 190.19,165.61$, 153.15, 153.04, 140.71, 128.99, 127.07, 120.84, 114.35, 113.78, $56.50,55.60,52.20$; HRMS (ESI) $m / z$ calcd for $\mathrm{C}_{13} \mathrm{H}_{14} \mathrm{O}_{5} \mathrm{Na}[\mathrm{M}+$ $\mathrm{Na}$ 2 273.0739, found 273.0747 [M+Na].
(E)-Methyl 4-(3,4-dimethoxyphenyl)-4-oxobut-2-enoate (8h). Yellow solid (46\%). Mp: 97.7-99.0 ${ }^{\circ} \mathrm{C} .{ }^{1} \mathrm{H}$ NMR $(400 \mathrm{MHz}$, DMSO- $\left.d_{6}\right) \delta 8.01(\mathrm{~d}, J=15.2 \mathrm{~Hz}, 1 \mathrm{H}), 7.79-7.77(\mathrm{~m}, 1 \mathrm{H}), 7.52-$ $7.51(\mathrm{~m}, 1 \mathrm{H}), 7.12-7.10(\mathrm{~m}, 1 \mathrm{H}), 6.73(\mathrm{~d}, J=15.2 \mathrm{~Hz}, 1 \mathrm{H}), 3.88(\mathrm{~s}$, $3 \mathrm{H}), 3.84(\mathrm{~s}, 3 \mathrm{H}), 3.78(\mathrm{~s}, 3 \mathrm{H}) ;{ }^{13} \mathrm{C}$ NMR (125 MHz, DMSO- $\left.d_{6}\right)$ $\delta$ 186.98, 165.53, 154.07, 149.02, 136.77, 130.52, 129.02, 124.32, 110.95, 110.39, 55.85, 55.53, 52.16; HRMS (ESI) $\mathrm{m} / \mathrm{z}$ calcd for $\mathrm{C}_{13} \mathrm{H}_{14} \mathrm{O}_{5} \mathrm{Na}[\mathrm{M}+\mathrm{Na}] 273.0739$, found 273.0733 [M+Na].

(E)-Methyl 4-(benzo[d][1,3] dioxol-5-yl)-4-oxobut-2-enoate (8i). White solid (46\%). Mp: 132.1-133.6 ${ }^{\circ} \mathrm{C} .{ }^{1} \mathrm{H}$ NMR $(500 \mathrm{MHz}$, DMSO- $\left.d_{6}\right) \delta 7.95(\mathrm{~d}, J=15.5 \mathrm{~Hz}, 1 \mathrm{H}), 7.75-7.73(\mathrm{~m}, 1 \mathrm{H}), 7.52-$ $7.51(\mathrm{~m}, 1 \mathrm{H}), 7.10-7.08(\mathrm{~m}, 1 \mathrm{H}), 6.71(\mathrm{~d}, J=15.5 \mathrm{~Hz}, 1 \mathrm{H}), 6.18(\mathrm{~s}$, $2 \mathrm{H}), 3.78(\mathrm{~s}, 3 \mathrm{H}) ;{ }^{13} \mathrm{C}$ NMR $\left(125 \mathrm{MHz}, \mathrm{DMSO}-d_{6}\right) \delta 186.89$, 165.46, 152.47, 148.30, 136.91, 130.79, 130.76, 126.25, 108.32, 107.66, 102.36, 52.19; MS-ESI $(\mathrm{m} / \mathrm{z}): 235.15[\mathrm{M}+\mathrm{Na}]$.

(E)-Methyl 4-(2,3-dihydrobenzofuran-5-yl)-4-oxobut-2-enoate (8j). Yellow solid (45\%). Mp: 83.3-84.5 ${ }^{\circ} \mathrm{C} .{ }^{1} \mathrm{H}$ NMR $(400 \mathrm{MHz}$, $\left.\mathrm{CDCl}_{3}\right) \delta 7.94-7.86(\mathrm{~m}, 3 \mathrm{H}), 6.89-6.84(\mathrm{~m}, 2 \mathrm{H}), 4.69(\mathrm{t}, J=8.8 \mathrm{~Hz}$, $2 \mathrm{H}), 3.84(\mathrm{~s}, 3 \mathrm{H}), 3.28(\mathrm{t}, J=8.8 \mathrm{~Hz}, 2 \mathrm{H}) ;{ }^{13} \mathrm{C}$ NMR $(125 \mathrm{MHz}$, DMSO- $\left.d_{6}\right) \delta 186.85,165.53,164.89,137.22,131.11,130.35$, 129.32, 128.88, 126.36, 109.21, 72.45, 52.15, 28.25; HRMS (ESI) $m / z$ calcd for $\mathrm{C}_{13} \mathrm{H}_{12} \mathrm{O}_{4} \mathrm{Na}[\mathrm{M}+\mathrm{Na}] 255.0633$, found 255.0627 [M $+\mathrm{Na}]$.

(E)-Methyl 4-([1,1'-biphenyl]-4 yl)-4-oxobut-2-enoate (8k). Yellow solid (42\%). Mp: 116.0-118.6 ${ }^{\circ} \mathrm{C} .{ }^{1} \mathrm{H}$ NMR $(400 \mathrm{MHz}$, DMSO- $\left.d_{6}\right) \delta 8.15-8.13(\mathrm{~m}, 2 \mathrm{H}), 8.02(\mathrm{~d}, J=15.6 \mathrm{~Hz}, 1 \mathrm{H}), 7.90-$ $7.88(\mathrm{~m}, 2 \mathrm{H}), 7.81-7.75(\mathrm{~m}, 2 \mathrm{H}), 7.55-7.51(\mathrm{~m}, 2 \mathrm{H}), 7.47-7.43$ $(\mathrm{m}, 1 \mathrm{H}), 6.78(\mathrm{~d}, J=15.6 \mathrm{~Hz}, 1 \mathrm{H}), 3.80(\mathrm{~s}, 3 \mathrm{H}) ;{ }^{13} \mathrm{C}$ NMR $(125$ MHz, DMSO- $\left.d_{6}\right) \delta 188.65,165.43,145.40,138.65,136.93,134.85$, 131.14, 129.64, 129.15, 128.64, 127.21, 127.07, 52.25; HRMS (ESI) $\mathrm{m} / z$ calcd for $\mathrm{C}_{17} \mathrm{H}_{14} \mathrm{O}_{3} \mathrm{Na}[\mathrm{M}+\mathrm{Na}] 289.0841$, found $289.0836[\mathrm{M}+\mathrm{Na}]$.

(E)-Methyl 4-oxo-4-(4-phenoxyphenyl) but-2-enoate (8l). Yellow solid (44\%). Mp: 92.0-93.5 ${ }^{\circ} \mathrm{C} .{ }^{1} \mathrm{H}$ NMR (400 MHz, DMSO- $d_{6}$ ) $\delta$ 8.12-8.07 (m, 2H), $7.96(\mathrm{~d}, J=15.6 \mathrm{~Hz}, 1 \mathrm{H}), 7.52-7.46(\mathrm{~m}, 2 \mathrm{H})$, 7.31-7.25 (m, 1H), 7.19-7.14 (m, 2H), 7.11-7.06 (m, 2H), 6.74 (d, $J=15.6 \mathrm{~Hz}, 1 \mathrm{H}), 3.78(\mathrm{~s}, 3 \mathrm{H}) ;{ }^{13} \mathrm{C} \mathrm{NMR}\left(125 \mathrm{MHz}, \mathrm{DMSO}-d_{6}\right)$ $\delta 187.48,165.45,162.17,154.64,136.87,131.64,130.93,130.44$, 130.40, 125.08, 120.27, 117.29, 52.23; MS-ESI $(\mathrm{m} / \mathrm{z}): 305.13[\mathrm{M}+$ $\mathrm{Na}$.

(E)-Methyl 4-(naphthalen-1-yl)-4-oxobut-2-enoate (8m). Yellow oil (42\%). ${ }^{1} \mathrm{H}$ NMR (500 MHz, DMSO- $\left.d_{6}\right) \delta 8.51-8.49(\mathrm{~m}, 1 \mathrm{H})$, 8.23-8.22 (m, 1H), 8.10-8.04 (m, 2H), $7.76(\mathrm{~d}, J=15.5 \mathrm{~Hz}, 1 \mathrm{H})$, 7.71-7.60 (m, 3H), 6.69 (d, $J=15.5 \mathrm{~Hz}, 1 \mathrm{H}), 3.79(\mathrm{~s}, 3 \mathrm{H}) ;{ }^{13} \mathrm{C}$ NMR $\left(125 \mathrm{MHz}\right.$, DMSO- $\left.d_{6}\right) \delta 192.55,165.34,139.95,133.59$, $133.50,133.45,131.52$, 129.96, 129.74, 128.65, 128.12, 126.65, 125.12, 124.72, 52.16; HRMS (ESI) $\mathrm{m} / z$ calcd for $\mathrm{C}_{15} \mathrm{H}_{12} \mathrm{O}_{3} \mathrm{Na}$ $[\mathrm{M}+\mathrm{Na}] 263.0684$, found $263.0674[\mathrm{M}+\mathrm{Na}]$.

(E)-Methyl 4-(2,4-dichlorophenyl)-4-oxobut-2-enoate (8n). Yellow solid (44\%). Mp: 98.7-100.1 ${ }^{\circ} \mathrm{C} .{ }^{1} \mathrm{H}$ NMR $(400 \mathrm{MHz}$, $\left.\mathrm{CDCl}_{3}\right) \delta 7.54(\mathrm{~d}, J=15.6 \mathrm{~Hz}, 1 \mathrm{H}), 7.50-7.44(\mathrm{~m}, 2 \mathrm{H}), 7.38-7.36$ (m, 1H), 6.69 (d, $J=15.6 \mathrm{~Hz}, 1 \mathrm{H}), 3.83$ (s, 3H); HRMS (ESI) $\mathrm{m} / z$ calcd for $\mathrm{C}_{11} \mathrm{H}_{7} \mathrm{Cl}_{2} \mathrm{O}_{3}[\mathrm{M}-\mathrm{H}]$ 256.9789, found 256.9756 $[\mathrm{M}-\mathrm{H}]$.

(E)-Methyl 4-(4-nitrophenyl)-4-oxobut-2-enoate (8o). Yellow solid (45\%). Mp: 105.9-107.0 ${ }^{\circ} \mathrm{C} .{ }^{1} \mathrm{H}$ NMR (400 MHz, $\mathrm{CDCl}_{3}$ ) 
$\delta$ 8.38-8.35 (m, 2H), 8.16-8.14 (m, 2H), $7.88(\mathrm{~d}, J=15.6 \mathrm{~Hz}, 1 \mathrm{H})$, $6.95(\mathrm{~d}, J=15.6 \mathrm{~Hz}, 1 \mathrm{H}), 3.87(\mathrm{~s}, 3 \mathrm{H})$; HRMS (ESI) $\mathrm{m} / z$ calcd for $\mathrm{C}_{22} \mathrm{H}_{17} \mathrm{~N}_{2} \mathrm{O}_{10}[2 \mathrm{M}-\mathrm{H}]$ 469.0883, found $469.0875[2 \mathrm{M}-\mathrm{H}]$.

(E)-Methyl 4-(4-bromophenyl)-4-oxobut-2-enoate (8p). Yellow solid (46\%). Mp: $77.8-79.0{ }^{\circ} \mathrm{C} .{ }^{1} \mathrm{H}$ NMR $\left(400 \mathrm{MHz}, \mathrm{CDCl}_{3}\right) \delta 7.87$ $(\mathrm{d}, J=15.6 \mathrm{~Hz}, 1 \mathrm{H}), 7.87-7.85(\mathrm{~m}, 2 \mathrm{H}), 7.67-7.65(\mathrm{~m}, 2 \mathrm{H}), 6.90$ $(\mathrm{d}, J=15.6 \mathrm{~Hz}, 1 \mathrm{H}), 3.85(\mathrm{~s}, 3 \mathrm{H}) ;{ }^{13} \mathrm{C}$ NMR $\left(125 \mathrm{MHz}, \mathrm{DMSO}-d_{6}\right)$ $\delta 188.50,165.33,136.60,135.01,132.12$, 131.50, 130.84, 128.36, 52.27; HRMS (ESI) $m / z$ calcd for $\mathrm{C}_{11} \mathrm{H}_{9} \mathrm{BrO}_{3} \mathrm{Na}[\mathrm{M}+\mathrm{Na}]$ 290.9633, found $290.9616[\mathrm{M}+\mathrm{Na}]$.

(E)-Methyl 4-(furan-2-yl)-4-oxobut-2-enoate (8q). Yellow solid (44\%). Mp: 90.7-92.8 ${ }^{\circ} \mathrm{C} .{ }^{1} \mathrm{H}$ NMR $\left(400 \mathrm{MHz}, \mathrm{CDCl}_{3}\right) \delta 7.77$ (d, $J$ $=15.6 \mathrm{~Hz}, 1 \mathrm{H}), 7.70-7.69(\mathrm{~m}, 1 \mathrm{H}), 7.39-7.38(\mathrm{~m}, 1 \mathrm{H}), 6.99(\mathrm{~d}, J=$ $15.6 \mathrm{~Hz}, 1 \mathrm{H}), 6.63-6.62(\mathrm{~m}, 1 \mathrm{H}), 3.85$ (s, 3H); ${ }^{13} \mathrm{C}$ NMR (125 MHz, DMSO- $\left.d_{6}\right) \delta 175.46,165.27,151.97,149.73,136.10,130.72$, 121.68, 113.29, 52.24; HRMS (ESI) $m / z$ calcd for $\mathrm{C}_{9} \mathrm{H}_{7} \mathrm{O}_{4}[\mathrm{M}-\mathrm{H}]$ 179.0362, found $179.0350[\mathrm{M}-\mathrm{H}]$.

(E)-Methyl 4-oxopent-2-enoate (8r). White solid (41\%). Mp: 61.9-63.2 ${ }^{\circ} \mathrm{C} .{ }^{1} \mathrm{H}$ NMR $\left(400 \mathrm{MHz}, \mathrm{CDCl}_{3}\right) \delta 7.02(\mathrm{~d}, J=16.0 \mathrm{~Hz}$, $1 \mathrm{H}), 6.65$ (d, $J=16.0 \mathrm{~Hz}, 1 \mathrm{H}), 3.81$ (s, 3H), 2.35 (s, 3H); HRMS (ESI) $\mathrm{m} / z$ calcd for $\mathrm{C}_{6} \mathrm{H}_{7} \mathrm{O}_{3}[\mathrm{M}-\mathrm{H}] 127.0412$, found $127.0392[\mathrm{M}$ $-\mathrm{H}]$.

(E)-Methyl 4-cyclohexyl-4-oxobut-2-enoate (8s). White solid (43\%). Mp: 52.3-54.6 ${ }^{\circ} \mathrm{C} .{ }^{1} \mathrm{H}$ NMR $\left(400 \mathrm{MHz}, \mathrm{CDCl}_{3}\right) \delta 7.19$ (d, $J$ $=16.0 \mathrm{~Hz}, 1 \mathrm{H}), 6.71(\mathrm{~d}, J=16.0 \mathrm{~Hz}, 1 \mathrm{H}), 3.81(\mathrm{~s}, 3 \mathrm{H}), 2.61-2.55$ (m, 1H), 1.89-1.68 (m, 5H), 1.42-1.17 (m, 5H); ${ }^{13} \mathrm{C}$ NMR (125 MHz, DMSO- $\left.d_{6}\right) \delta 202.32,165.59,138.83,129.68,52.19,47.97$, $27.68,25.37,24.88$; HRMS (ESI) $m / z$ calcd for $\mathrm{C}_{11} \mathrm{H}_{16} \mathrm{O}_{3} \mathrm{Na}[\mathrm{M}+$ $\mathrm{Na}$ ] 219.0997, found 219.1006 [M $+\mathrm{Na}$ ].

(E)-Methyl 4-cyclopropyl-4-oxobut-2-enoate (8t). Yellow oil (37\%). ${ }^{1} \mathrm{H}$ NMR $\left(400 \mathrm{MHz}, \mathrm{DMSO}-d_{6}\right) \delta 7.13(\mathrm{~d}, J=16.0 \mathrm{~Hz}, 1 \mathrm{H})$, $6.79(\mathrm{~d}, J=16.0 \mathrm{~Hz}, 1 \mathrm{H}), 3.76(\mathrm{~s}, 3 \mathrm{H}), 2.56-2.51(\mathrm{~m}, 1 \mathrm{H}), 1.06-$ $0.95(\mathrm{~m}, 4 \mathrm{H}) ;{ }^{13} \mathrm{C}$ NMR (125 MHz, DMSO- $\left.d_{6}\right) \delta 199.42,165.61$, 139.62, 129.80, 52.15, 19.44, 11.76; HRMS (ESI) $\mathrm{m} / \mathrm{z}$ calcd for $\mathrm{C}_{8} \mathrm{H}_{10} \mathrm{O}_{3} \mathrm{Na}[\mathrm{M}+\mathrm{Na}]$ 177.0528, found $177.0520[\mathrm{M}+\mathrm{Na}]$.

(E)-Ethyl 4-(4-methoxyphenyl)-4-oxobut-2-enoate (9a). Yellow solid (46\%), mp: $41.2-42.7{ }^{\circ} \mathrm{C} .{ }^{1} \mathrm{H}$ NMR (500 MHz, DMSO- $d_{6}$ ) $\delta$ 8.06-8.05 (m, 2H), $7.99(\mathrm{~d}, J=15.5 \mathrm{~Hz}, 1 \mathrm{H}), 7.11-7.10(\mathrm{~m}, 2 \mathrm{H})$, 7.05-7.03 (m, 1H), 6.69 (d, $J=15.5 \mathrm{~Hz}, 1 \mathrm{H}), 4.18-4.16(\mathrm{~m}, 2 \mathrm{H})$, 3.88 (s, 3H), 3.28-3.24 (m, 2H), 1.37 (s, 9H); ${ }^{13} \mathrm{C}$ NMR (125 MHz, DMSO- $\left.d_{6}\right) \delta 187.14,165.00,163.95,136.81,131.36,130.91$, 129.00, 114.33, 60.93, 55.66, 13.99; HRMS (ESI) $\mathrm{m} / \mathrm{z}$ calcd for $\mathrm{C}_{13} \mathrm{H}_{14} \mathrm{O}_{4} \mathrm{Na}[\mathrm{M}+\mathrm{Na}$ ] 257.0790, found 257.0792 [M + Na].

(E)-Ethyl 4-oxo-4-phenylbut-2-enoate (9b). Yellow oil $(46 \%) .{ }^{1} \mathrm{H}$ NMR (500 MHz, DMSO- $\left.d_{6}\right) \delta 8.05-8.03(\mathrm{~m}, 2 \mathrm{H}), 7.95(\mathrm{~d}, J=$ $15.5 \mathrm{~Hz}, 1 \mathrm{H}), 7.75-7.69(\mathrm{~m}, 1 \mathrm{H}), 7.63-7.56(\mathrm{~m}, 2 \mathrm{H}), 6.73(\mathrm{~d}, J=$ $15.5 \mathrm{~Hz}, 1 \mathrm{H}), 4.25(\mathrm{q}, J=7.0 \mathrm{~Hz}, 2 \mathrm{H}), 1.28(\mathrm{t}, J=7.0 \mathrm{~Hz}, 3 \mathrm{H}) ;{ }^{13} \mathrm{C}$ NMR (125 MHz, DMSO- $\left.d_{6}\right) \delta 189.15,164.85,136.64,136.02$, 134.01, 131.57, 128.99, 128.78, 60.98, 13.95; HRMS (ESI) $\mathrm{m} / \mathrm{z}$ calcd for $\mathrm{C}_{11} \mathrm{H}_{10} \mathrm{O}_{3} \mathrm{Na}[\mathrm{M}+\mathrm{Na}]$ 213.0528, found 213.0538 [M $\left.+\mathrm{Na}\right]$.

(E)-Ethyl 4-oxo-4-(p-tolyl) but-2-enoate (9c). Yellow oil (43\%). ${ }^{1} \mathrm{H}$ NMR $\left(500 \mathrm{MHz}, \mathrm{DMSO}-d_{6}\right) \delta 7.96-7.92(\mathrm{~m}, 3 \mathrm{H}), 7.40-7.38(\mathrm{~m}$, $2 \mathrm{H}), 6.71(\mathrm{~d}, J=15.5 \mathrm{~Hz}, 1 \mathrm{H}), 4.25(\mathrm{q}, J=7.0 \mathrm{~Hz}, 2 \mathrm{H}), 2.41(\mathrm{~s}$, $3 \mathrm{H}), 1.28(\mathrm{t}, J=7.0 \mathrm{~Hz}, 3 \mathrm{H}) ;{ }^{13} \mathrm{C}$ NMR (125 MHz, DMSO- $\left.d_{6}\right)$ $\delta 188.51,164.92,144.77,136.74,133.58,131.30,129.60,128.96$, $60.97,21.23,13.98$; HRMS (ESI) $m / z$ calcd for $\mathrm{C}_{13} \mathrm{H}_{14} \mathrm{O}_{3} \mathrm{Na}[\mathrm{M}+$ $\mathrm{Na}$ ] 241.0841, found 241.0840 [M + Na].
(E)-Ethyl 4-(4-ethoxyphenyl)-4-oxobut-2-enoate (9d). Yellow solid (40\%), mp: 54.4-55.7 ${ }^{\circ} \mathrm{C}$. ${ }^{1} \mathrm{H}$ NMR (400 MHz, $\mathrm{CDCl}_{3}$ ) $\delta 8.03-7.97(\mathrm{~m}, 2 \mathrm{H}), 7.92(\mathrm{~d}, J=15.6 \mathrm{~Hz}, 1 \mathrm{H}), 6.99-6.93(\mathrm{~m}, 2 \mathrm{H})$, $6.87(\mathrm{~d}, J=15.6 \mathrm{~Hz}, 1 \mathrm{H}), 4.30(\mathrm{q}, J=7.2 \mathrm{~Hz}, 2 \mathrm{H}), 4.13(\mathrm{q}, J=$ $6.8 \mathrm{~Hz}, 2 \mathrm{H}), 1.46(\mathrm{t}, J=6.8 \mathrm{~Hz}, 3 \mathrm{H}), 1.35(\mathrm{t}, J=7.2 \mathrm{~Hz}, 3 \mathrm{H}) ;{ }^{13} \mathrm{C}$ NMR (125 MHz, DMSO- $\left.d_{6}\right) \delta 187.15,165.02,163.28,136.90$, 131.40, 130.88, 128.84, 114.72, 63.75, 60.94, 14.44, 14.02; HRMS (ESI) $\mathrm{m} / z$ calcd for $\mathrm{C}_{14} \mathrm{H}_{16} \mathrm{O}_{4} \mathrm{Na}[\mathrm{M}+\mathrm{Na}] 271.0946$, found $271.0953[\mathrm{M}+\mathrm{Na}]$.

(E)-Ethyl 4-(2-methoxyphenyl)-4-oxobut-2-enoate (9e). Yellow solid (41\%), mp: 50.1-51.5 ${ }^{\circ} \mathrm{C} .{ }^{1} \mathrm{H}$ NMR (500 MHz, DMSO- $d_{6}$ ) $\delta 7.66(\mathrm{~d}, J=15.5 \mathrm{~Hz}, 1 \mathrm{H}), 7.64-7.57(\mathrm{~m}, 2 \mathrm{H}), 7.24-7.22(\mathrm{~m}, 1 \mathrm{H})$, $7.10-7.07(\mathrm{~m}, 1 \mathrm{H}), 6.57(\mathrm{~d}, J=15.5 \mathrm{~Hz}, 1 \mathrm{H}), 4.22(\mathrm{q}, J=7.0 \mathrm{~Hz}$, $2 \mathrm{H}), 1.26(\mathrm{t}, J=7.0 \mathrm{~Hz}, 3 \mathrm{H}) ;{ }^{13} \mathrm{C}$ NMR (125 MHz, DMSO- $\left.d_{6}\right)$ $\delta$ 190.62, 165.11, 158.65, 140.68, 134.76, 130.10, 129.32, 126.81, 120.83, 112.70, 60.91, 56.00, 13.97; HRMS (ESI) $\mathrm{m} / \mathrm{z}$ calcd for $\mathrm{C}_{13} \mathrm{H}_{14} \mathrm{O}_{4} \mathrm{Na}[\mathrm{M}+\mathrm{Na}] 257.0790$, found 257.0778 [M + Na].

(E)-Ethyl 4-(3-methoxyphenyl)-4-oxobut-2-enoate (9f). Yellow oil (40\%). ${ }^{1} \mathrm{H}$ NMR $\left(500 \mathrm{MHz}, \mathrm{DMSO}-d_{6}\right) \delta 7.93(\mathrm{~d}, J=15.5 \mathrm{~Hz}, 1 \mathrm{H})$, 7.68-7.62 (m, 1H), 7.55-7.47 (m, 2H), 7.30-7.28 (m, 1H), 6.73 (d, $J=15.5 \mathrm{~Hz}, 1 \mathrm{H}), 4.25$ (q, $J=7.0 \mathrm{~Hz}, 2 \mathrm{H}), 3.85(\mathrm{~s}, 3 \mathrm{H}), 1.28(\mathrm{t}, J=$ $7.0 \mathrm{~Hz}, 3 \mathrm{H}) ;{ }^{13} \mathrm{C}$ NMR $\left(125 \mathrm{MHz}, \mathrm{DMSO}-d_{6}\right) \delta 188.99,164.88$, 159.61, 137.42, 136.74, 131.65, 130.22, 121.52, 120.32, 112.82, $61.00,55.39,13.98$; HRMS (ESI) $m / z$ calcd for $\mathrm{C}_{13} \mathrm{H}_{14} \mathrm{O}_{4} \mathrm{Na}[\mathrm{M}+$ $\mathrm{Na}$ ] 257.0790, found 257.0793 [M $+\mathrm{Na}]$.

(E)-Ethyl 4-(2,5-dimethoxyphenyl)-4-oxobut-2-enoate (9g). Yellow solid (42\%). Mp: 66.2-67.5 ${ }^{\circ} \mathrm{C} .{ }^{1} \mathrm{H}$ NMR $(500 \mathrm{MHz}$, DMSO- $\left.d_{6}\right) \delta 7.68(\mathrm{~d}, J=15.5 \mathrm{~Hz}, 1 \mathrm{H}), 7.22-7.17(\mathrm{~m}, 2 \mathrm{H}), 7.11-$ $7.10(\mathrm{~m}, 1 \mathrm{H}), 6.57$ (d, $J=15.5 \mathrm{~Hz}, 1 \mathrm{H}), 4.22(\mathrm{q}, J=7.0 \mathrm{~Hz}, 2 \mathrm{H})$, $3.84(\mathrm{~s}, 3 \mathrm{H}), 3.75(\mathrm{~s}, 3 \mathrm{H}), 1.26(\mathrm{t}, J=7.0 \mathrm{~Hz}, 3 \mathrm{H}) ;{ }^{13} \mathrm{C} \mathrm{NMR}(125$ MHz, DMSO- $\left.d_{6}\right) \delta 190.18,165.10,153.15,153.02,140.61,129.35$, 127.08, 120.76, 114.33, 113.77, 60.90, 56.46, 55.57, 13.96; HRMS (ESI) $\mathrm{m} / z$ calcd for $\mathrm{C}_{14} \mathrm{H}_{16} \mathrm{O}_{5} \mathrm{Na}[\mathrm{M}+\mathrm{Na}] 287.0895$, found $287.0895[\mathrm{M}+\mathrm{Na}]$.

(E)-Ethyl 4-(3,4-dimethoxyphenyl)-4-oxobut-2-enoate (9h). Yellow solid (43\%). Mp: 92.6-94.7 ${ }^{\circ} \mathrm{C} .{ }^{1} \mathrm{H}$ NMR $(400 \mathrm{MHz}$, DMSO- $\left.d_{6}\right) \delta 8.00(\mathrm{~d}, J=15.6 \mathrm{~Hz}, 1 \mathrm{H}), 7.79-7.77(\mathrm{~m}, 1 \mathrm{H}), 7.52-$ $7.51(\mathrm{~m}, 1 \mathrm{H}), 7.13-7.10(\mathrm{~m}, 1 \mathrm{H}), 6.72(\mathrm{~d}, J=15.6 \mathrm{~Hz}, 1 \mathrm{H}), 4.24(\mathrm{q}$, $J=7.2 \mathrm{~Hz}, 2 \mathrm{H}), 3.88(\mathrm{~s}, 3 \mathrm{H}), 3.84(\mathrm{~s}, 3 \mathrm{H}), 1.28(\mathrm{t}, J=7.2 \mathrm{~Hz}, 3 \mathrm{H})$; ${ }^{13} \mathrm{C}$ NMR (125 MHz, DMSO- $d_{6}$ ) $\delta 187.09,165.06,154.08,149.04$, $136.75,130.93,129.04,124.38,111.01,110.41$, 60.95, 55.89, $55.57,14.03$; HRMS (ESI) $m / z$ calcd for $\mathrm{C}_{14} \mathrm{H}_{16} \mathrm{O}_{5} \mathrm{Na}[\mathrm{M}+\mathrm{Na}]$ 287.0895, found $287.0878[\mathrm{M}+\mathrm{Na}]$.

(E)-Ethyl 4-(benzo[d][1,3] dioxol-5-yl)-4-oxobut-2-enoate (9i). Yellow solid (45\%). Mp: 90.8-93.0 ${ }^{\circ} \mathrm{C}$. ${ }^{1} \mathrm{H}$ NMR $(500 \mathrm{MHz}$, DMSO- $\left.d_{6}\right) \delta 7.93(\mathrm{~d}, J=15.5 \mathrm{~Hz}, 1 \mathrm{H}), 7.75-7.73(\mathrm{~m}, 1 \mathrm{H}), 7.51-$ $7.50(\mathrm{~m}, 1 \mathrm{H}), 7.09-7.08(\mathrm{~m}, 1 \mathrm{H}), 6.69(\mathrm{~d}, J=15.5 \mathrm{~Hz}, 1 \mathrm{H}), 6.18(\mathrm{~s}$, $2 \mathrm{H}), 4.24$ (q, $J=7.0 \mathrm{~Hz}, 2 \mathrm{H}), 1.28(\mathrm{t}, J=7.0 \mathrm{~Hz}, 3 \mathrm{H}) ;{ }^{13} \mathrm{C} \mathrm{NMR}$ $\left(125 \mathrm{MHz}, \mathrm{DMSO}-d_{6}\right) \delta 186.88,164.97,152.45,148.29,136.74$, 131.12, 130.79, 126.22, 108.30, 107.64, 102.36, 60.95, 14.01; MSESI $(\mathrm{m} / \mathrm{z}): 249.13[\mathrm{M}+\mathrm{Na}]$.

(E)-Ethyl 4-(2,3-dihydrobenzofuran-5-yl)-4-oxobut-2-enoate (9j). Yellow solid (44\%). Mp: 57.7-59.4 ${ }^{\circ} \mathrm{C}$. ${ }^{1} \mathrm{H}$ NMR $(500 \mathrm{MHz}$, DMSO- $\left.d_{6}\right) \delta$ 7.96-7.89 (m, 3H), 6.92-6.90 (m, 1H), 6.69 (d, $J=$ $15.5 \mathrm{~Hz}, 1 \mathrm{H}), 4.67$ (t, $J=9.0 \mathrm{~Hz}, 2 \mathrm{H}), 4.24(\mathrm{q}, J=7.0 \mathrm{~Hz}, 2 \mathrm{H}), 3.26$ $(\mathrm{t}, J=9.0 \mathrm{~Hz}, 2 \mathrm{H}), 1.28(\mathrm{t}, J=7.0 \mathrm{~Hz}, 3 \mathrm{H}) ;{ }^{13} \mathrm{C} \mathrm{NMR}(125 \mathrm{MHz}$, 
DMSO- $\left.d_{6}\right) \delta 186.83,165.03,164.87,137.03,131.08,130.70$, 129.32, 128.85, 126.32, 72.43, 60.91, 28.25, 14.01; HRMS (ESI) $m / z$ calcd for $\mathrm{C}_{14} \mathrm{H}_{14} \mathrm{O}_{4} \mathrm{Na}[\mathrm{M}+\mathrm{Na}] 269.0790$, found 269.0791 $[\mathrm{M}+\mathrm{Na}]$.

(E)-Ethyl 4-([1,1'-biphenyl]-4 yl)-4-oxobut-2-enoate (9k). Yellow solid (43\%). Mp: 80.5-82.7 ${ }^{\circ} \mathrm{C} .{ }^{1} \mathrm{H}$ NMR (400 MHz, DMSO- $d_{6}$ ) $\delta 8.15-8.13(\mathrm{~m}, 2 \mathrm{H}), 8.00(\mathrm{~d}, J=15.6 \mathrm{~Hz}, 1 \mathrm{H}), 7.90-7.88(\mathrm{~m}, 2 \mathrm{H})$, 7.78-7.76 (m, 2H), 7.55-7.51 (m, 2H), 7.47-7.43 (m, 1H), $6.76(\mathrm{~d}$, $J=15.6 \mathrm{~Hz}, 1 \mathrm{H}), 4.26(\mathrm{q}, J=7.2 \mathrm{~Hz}, 2 \mathrm{H}), 1.29(\mathrm{t}, J=7.2 \mathrm{~Hz}, 3 \mathrm{H})$; ${ }^{13} \mathrm{C}$ NMR $\left(125 \mathrm{MHz}, \mathrm{DMSO}-d_{6}\right) \delta 188.63,164.93,145.38,138.65$, 136.74, 134.85, 131.51, 129.61, 129.13, 128.61, 127.19, 127.06, 61.02, 14.01; HRMS (ESI) $\mathrm{m} / z$ calcd for $\mathrm{C}_{18} \mathrm{H}_{16} \mathrm{O}_{3} \mathrm{Na}[\mathrm{M}+\mathrm{Na}]$ 303.0997, found 303.0990 [M+ Na].

(E)-Ethyl 4-oxo-4-(4-phenoxyphenyl) but-2-enoate (9l). Yellow solid (41\%). Mp: 53.7-55.5 ${ }^{\circ} \mathrm{C} .{ }^{1} \mathrm{H}$ NMR (400 MHz, DMSO- $d_{6}$ ) $\delta$ 8.12-8.06 (m, 2H), $7.94(\mathrm{~d}, J=15.6 \mathrm{~Hz}, 1 \mathrm{H}), 7.52-7.45(\mathrm{~m}, 2 \mathrm{H})$, 7.31-7.25 (m, 1H), 7.19-7.14 (m, 2H), 7.11-7.06 (m, 2H), $6.72(\mathrm{~d}$, $J=15.6 \mathrm{~Hz}, 1 \mathrm{H}), 4.24(\mathrm{q}, J=7.2 \mathrm{~Hz}, 2 \mathrm{H}), 1.28(\mathrm{t}, J=7.2 \mathrm{~Hz}, 3 \mathrm{H})$; ${ }^{13} \mathrm{C}$ NMR $\left(125 \mathrm{MHz}, \mathrm{DMSO}-d_{6}\right) \delta 187.46,164.93,162.12,154.65$, 136.69, 131.59, 131.27, 130.75, 130.40, 125.04, 120.23, 117.27, 60.98, 13.99; HRMS (ESI) $\mathrm{m} / z$ calcd for $\mathrm{C}_{18} \mathrm{H}_{16} \mathrm{O}_{4} \mathrm{Na}[\mathrm{M}+\mathrm{Na}]$ 319.0946, found 319.0926 [M + Na].

(E)-Ethyl 4-(naphthalen-1-yl)-4-oxobut-2-enoate (9m). Yellow oil (42\%). ${ }^{1} \mathrm{H}$ NMR (400 MHz, $\mathrm{CDCl}_{3}$ ) $\delta 8.52-8.50$ (m, 1H), 8.05-8.03 $(\mathrm{m}, 1 \mathrm{H}), 7.94-7.88(\mathrm{~m}, 1 \mathrm{H}), 7.87-7.85(\mathrm{~m}, 1 \mathrm{H}), 7.74(\mathrm{~d}, J=$ $15.6 \mathrm{~Hz}, 1 \mathrm{H}), 7.64-7.51(\mathrm{~m}, 3 \mathrm{H}), 6.78$ (d, $J=15.6 \mathrm{~Hz}, 1 \mathrm{H}), 4.30$ $(\mathrm{q}, J=7.2 \mathrm{~Hz}, 2 \mathrm{H}), 1.34(\mathrm{t}, J=7.2 \mathrm{~Hz}, 3 \mathrm{H}) ;{ }^{13} \mathrm{C} \mathrm{NMR}(125 \mathrm{MHz}$, DMSO- $\left.d_{6}\right) \delta 192.82,164.88,139.97,133.66,133.45,132.00$, 129.92, 129.72, 128.68, 128.15, 126.71, 125.10, 124.81, 61.03, 13.94; HRMS (ESI) $m / z$ calcd for $\mathrm{C}_{16} \mathrm{H}_{14} \mathrm{O}_{3} \mathrm{Na}[\mathrm{M}+\mathrm{Na}] 277.0841$, found $277.0837[\mathrm{M}+\mathrm{Na}]$.

(E)-Ethyl 4-(2,4-dichlorophenyl)-4-oxobut-2-enoate (9n). Yellow solid (43\%). Mp: 67.3-69.2 ${ }^{\circ} \mathrm{C} .{ }^{1} \mathrm{H}$ NMR (500 MHz, DMSO- $d_{6}$ ) $\delta$ 7.81-7.80 (m, 1H), 7.70-7.69 (m, 1H), 7.61-7.59 (m, 1H), 7.39 $(\mathrm{d}, J=16.0 \mathrm{~Hz}, 1 \mathrm{H}), 6.56(\mathrm{~d}, J=16.0 \mathrm{~Hz}, 1 \mathrm{H}), 4.22(\mathrm{q}, J=7.0 \mathrm{~Hz}$, $2 \mathrm{H}$ ), $1.25\left(\mathrm{t}, J=7.0 \mathrm{~Hz}, 3 \mathrm{H}\right.$ ); HRMS (ESI) $\mathrm{m} / z$ calcd for $\mathrm{C}_{12} \mathrm{H}_{10^{-}}$ $\mathrm{Cl}_{2} \mathrm{O}_{3} \mathrm{Na}[\mathrm{M}+\mathrm{Na}] 294.9918$, found $294.9918[\mathrm{M}+\mathrm{Na}]$.

(E)-Ethyl 4-(4-nitrophenyl)-4-oxobut-2-enoate (9o). Yellow solid (42\%). Mp: $69.4-71.5{ }^{\circ} \mathrm{C} .{ }^{1} \mathrm{H}$ NMR $\left(500 \mathrm{MHz}\right.$, DMSO- $\left.d_{6}\right) \delta 8.38-$ $8.35(\mathrm{~m}, 2 \mathrm{H}), 8.27-8.25(\mathrm{~m}, 2 \mathrm{H}), 7.93(\mathrm{~d}, J=15.5 \mathrm{~Hz}, 1 \mathrm{H}), 6.77$ (d, $J=15.5 \mathrm{~Hz}, 1 \mathrm{H}), 4.26$ (q, $J=7.0 \mathrm{~Hz}, 2 \mathrm{H}), 1.29(\mathrm{t}, J=7.0 \mathrm{~Hz}, 3 \mathrm{H})$; HRMS (ESI) $m / z$ calcd for $\mathrm{C}_{24} \mathrm{H}_{21} \mathrm{~N}_{2} \mathrm{O}_{10}[2 \mathrm{M}-\mathrm{H}]$ 497.1196, found 497.1193 [2M $-\mathrm{H}]$.

(E)-Ethyl 4-(4-bromophenyl)-4-oxobut-2-enoate (9p). Yellow solid (44\%). Mp: 62.3-64.7 ${ }^{\circ} \mathrm{C} .{ }^{1} \mathrm{H}$ NMR (500 MHz, DMSO- $d_{6}$ ) $\delta$ 7.99-7.97 (m, 2H), $7.91(\mathrm{~d}, J=15.5 \mathrm{~Hz}, 1 \mathrm{H}), 7.80-7.78(\mathrm{~m}, 2 \mathrm{H})$, $6.74(\mathrm{~d}, J=15.5 \mathrm{~Hz}, 1 \mathrm{H}), 4.25(\mathrm{q}, J=7.0 \mathrm{~Hz}, 2 \mathrm{H}), 1.28(\mathrm{t}, J=$ $7.0 \mathrm{~Hz}, 3 \mathrm{H}) ;{ }^{13} \mathrm{C}$ NMR $\left(125 \mathrm{MHz}, \mathrm{DMSO}-d_{6}\right) \delta 188.50,164.83$, 136.42, 135.01, 132.10, 130.82, 128.33, 61.05, 14.00; HRMS (ESI) $m / z$ calcd for $\mathrm{C}_{12} \mathrm{H}_{11} \mathrm{BrO}_{3} \mathrm{Na}[\mathrm{M}+\mathrm{Na}] 306.9769$, found 306.9783 $[\mathrm{M}+\mathrm{Na}]$.

(E)-Ethyl 4-(furan-2-yl)-4-oxobut-2-enoate (9q). Yellow solid (46\%). Mp: 63.6-65.2 ${ }^{\circ} \mathrm{C} .{ }^{1} \mathrm{H}$ NMR $\left(400 \mathrm{MHz}, \mathrm{CDCl}_{3}\right) \delta 7.76(\mathrm{~d}, J$ $=15.6 \mathrm{~Hz}, 1 \mathrm{H}), 7.71-7.67(\mathrm{~m}, 1 \mathrm{H}), 7.38-7.37(\mathrm{~m}, 1 \mathrm{H}), 6.98(\mathrm{~d}, J=$ $15.6 \mathrm{~Hz}, 1 \mathrm{H}), 6.63-7.61(\mathrm{~m}, 1 \mathrm{H}), 4.30(\mathrm{q}, J=7.2 \mathrm{~Hz}, 2 \mathrm{H}), 1.35(\mathrm{t}, J$ $=7.2 \mathrm{~Hz}, 3 \mathrm{H}) ;{ }^{13} \mathrm{C}$ NMR $\left(125 \mathrm{MHz}, \mathrm{DMSO}-d_{6}\right) \delta 175.50,164.77$, 151.98, 149.68, 135.96, 131.08, 121.59, 113.27, 61.03, 13.98;
HRMS (ESI) $m / z$ calcd for $\mathrm{C}_{10} \mathrm{H}_{10} \mathrm{O}_{4} \mathrm{Na}[\mathrm{M}+\mathrm{Na}] 217.0477$, found $217.0456[\mathrm{M}+\mathrm{Na}]$.

(E)-Ethyl 4-oxopent-2-enoate (9r). Yellow oil (40\%). ${ }^{1} \mathrm{H}$ NMR $\left(400 \mathrm{MHz}, \mathrm{CDCl}_{3}\right) \delta 7.00(\mathrm{~d}, J=16.0 \mathrm{~Hz}, 1 \mathrm{H}), 6.63(\mathrm{~d}, J=16.0 \mathrm{~Hz}$, $1 \mathrm{H}), 4.25$ (q, $J=7.2 \mathrm{~Hz}, 2 \mathrm{H}), 2.34(\mathrm{~s}, 3 \mathrm{H}), 1.31$ (t, $J=7.2 \mathrm{~Hz}, 3 \mathrm{H})$; MS-ESI $(\mathrm{m} / \mathrm{z}): 165.09[\mathrm{M}+\mathrm{Na}]$.

(E)-Ethyl 4-cyclohexyl-4-oxobut-2-enoate (9s). Yellow oil (39\%). ${ }^{1} \mathrm{H} \mathrm{NMR}\left(400 \mathrm{MHz}, \mathrm{CDCl}_{3}\right) \delta 7.14(\mathrm{~d}, J=16.0 \mathrm{~Hz}, 1 \mathrm{H}), 6.70(\mathrm{~d}, J=$ $16.0 \mathrm{~Hz}, 1 \mathrm{H}), 4.26$ (q, $J=7.2 \mathrm{~Hz}, 2 \mathrm{H}), 2.60-2.53(\mathrm{~m}, 1 \mathrm{H}), 1.86-$ $1.65(\mathrm{~m}, 5 \mathrm{H}), 1.36-1.24(\mathrm{~m}, 5 \mathrm{H}) ;{ }^{13} \mathrm{C}$ NMR (125 MHz, DMSO- $\left.d_{6}\right)$ $\delta$ 202.12, 165.01, 138.59, 130.00, 60.87, 47.89, 27.71, 25.37, 24.88, 13.88; HRMS (ESI) $\mathrm{m} / z$ calcd for $\mathrm{C}_{12} \mathrm{H}_{18} \mathrm{O}_{3} \mathrm{Na}[\mathrm{M}+\mathrm{Na}]$ 233.1154, found 233.1162 [M $+\mathrm{Na}]$.

(E)-Ethyl 4-cyclopropyl-4-oxobut-2-enoate (9t). Yellow oil (40\%). ${ }^{1} \mathrm{H}$ NMR $\left(500 \mathrm{MHz}, \mathrm{CDCl}_{3}\right) \delta 7.17(\mathrm{~d}, J=16.0 \mathrm{~Hz}, 1 \mathrm{H}), 6.71(\mathrm{~d}, J=$ $16.0 \mathrm{~Hz}, 1 \mathrm{H}), 4.26(\mathrm{q}, J=7.0 \mathrm{~Hz}, 2 \mathrm{H}), 2.22-2.17(\mathrm{~m}, 1 \mathrm{H}), 1.32(\mathrm{t}, J$ $=7.0 \mathrm{~Hz}, 3 \mathrm{H}), 1.19-1.14(\mathrm{~m}, 2 \mathrm{H}), 1.04-1.00(\mathrm{~m}, 2 \mathrm{H}) ;{ }^{13} \mathrm{C} \mathrm{NMR}$ (125 MHz, DMSO- $d_{6}$ ) $\delta 199.54,165.16,139.58,130.26,60.99$, 19.37, 13.96, 11.77; MS-ESI $(\mathrm{m} / \mathrm{z}): 191.22$ [M + Na].

(E)-Isopropyl 4-(4-methoxyphenyl)-4-oxobut-2-enoate (10a). Yellow solid (45\%), mp: 43.3-44.7 ${ }^{\circ} \mathrm{C} .{ }^{1} \mathrm{H}$ NMR $(500 \mathrm{MHz}$, DMSO- $\left.d_{6}\right) \delta 8.06-8.04(\mathrm{~m}, 2 \mathrm{H}), 7.93(\mathrm{~d}, J=15.5 \mathrm{~Hz}, 1 \mathrm{H}), 7.11-$ $7.09(\mathrm{~m}, 2 \mathrm{H}), 6.67(\mathrm{~d}, J=15.5 \mathrm{~Hz}, 1 \mathrm{H}), 5.09-5.00(\mathrm{~m}, 1 \mathrm{H}), 3.87(\mathrm{~s}$, $3 \mathrm{H}), 1.29(\mathrm{~s}, 3 \mathrm{H}), 1.28(\mathrm{~s}, 3 \mathrm{H}) ;{ }^{13} \mathrm{C}$ NMR (125 MHz, DMSO- $\left.d_{6}\right)$ $\delta 187.13,164.50,163.94,136.66,131.32,129.01,114.33,68.53$, $55.65,21.49$; HRMS (ESI) $m / z$ calcd for $\mathrm{C}_{14} \mathrm{H}_{16} \mathrm{O}_{4} \mathrm{Na}[\mathrm{M}+\mathrm{Na}]$ 271.0946, found 271.0959 [M + Na].

(E)-Isopropyl 4-oxo-4-phenylbut-2-enoate (10b). Yellow oil (47\%). ${ }^{1} \mathrm{H}$ NMR (500 MHz, DMSO- $\left.d_{6}\right) \delta 8.07-8.01(\mathrm{~m}, 2 \mathrm{H}), 7.92$ $(\mathrm{d}, J=15.5 \mathrm{~Hz}, 1 \mathrm{H}), 7.74-7.70(\mathrm{~m}, 1 \mathrm{H}), 7.62-7.57(\mathrm{~m}, 2 \mathrm{H}), 6.70$ $(\mathrm{d}, J=15.5 \mathrm{~Hz}, 1 \mathrm{H}), 5.09-5.02(\mathrm{~m}, 1 \mathrm{H}), 1.29(\mathrm{~s}, 3 \mathrm{H}), 1.28(\mathrm{~s}, 3 \mathrm{H})$; HRMS (ESI) $m / z$ calcd for $\mathrm{C}_{13} \mathrm{H}_{14} \mathrm{O}_{3} \mathrm{Na}[\mathrm{M}+\mathrm{Na}] 241.0841$, found $241.0837[\mathrm{M}+\mathrm{Na}]$.

(E)-Isopropyl 4-oxo-4-(p-tolyl) but-2-enoate (10c). Yellow solid (44\%), mp: $60.2-61.9{ }^{\circ} \mathrm{C} .{ }^{1} \mathrm{H}$ NMR $\left(400 \mathrm{MHz}, \mathrm{CDCl}_{3}\right) \delta 7.92-7.86$ $(\mathrm{m}, 3 \mathrm{H}), 7.32-7.30(\mathrm{~m}, 2 \mathrm{H}), 6.85$ (d, $J=15.6 \mathrm{~Hz}, 1 \mathrm{H}), 5.20-5.12$ (m, 1H), $2.44(\mathrm{~s}, 3 \mathrm{H}), 1.33(\mathrm{~s}, 3 \mathrm{H}), 1.32(\mathrm{~s}, 3 \mathrm{H}) ;{ }^{13} \mathrm{C}$ NMR (125 MHz, DMSO- $\left.d_{6}\right) \delta 188.56,164.43,144.76,136.65,133.58,131.71$, 129.61, 128.96, 68.58, 21.48, 21.24; HRMS (ESI) $\mathrm{m} / \mathrm{z}$ calcd for $\mathrm{C}_{14} \mathrm{H}_{16} \mathrm{O}_{3} \mathrm{Na}[\mathrm{M}+\mathrm{Na}] 255.0997$, found 255.0982 [M + Na].

(E)-Isopropyl 4-(4-ethoxyphenyl)-4-oxobut-2-enoate (10d). Yellow solid (44\%), mp: 38.6-40.5 ${ }^{\circ} \mathrm{C}$. ${ }^{1} \mathrm{H}$ NMR $(500 \mathrm{MHz}$, DMSO- $\left.d_{6}\right) \delta 8.04-8.02(\mathrm{~m}, 2 \mathrm{H}), 7.93(\mathrm{~d}, J=15.5 \mathrm{~Hz}, 1 \mathrm{H}), 7.09-$ $7.07(\mathrm{~m}, 2 \mathrm{H}), 6.67$ (d, $J=15.5 \mathrm{~Hz}, 1 \mathrm{H}), 5.11-4.99(\mathrm{~m}, 1 \mathrm{H}), 4.15$ (q, $J=7.0 \mathrm{~Hz}, 2 \mathrm{H}), 1.36(\mathrm{t}, J=7.0 \mathrm{~Hz}, 3 \mathrm{H}), 1.29(\mathrm{~s}, 3 \mathrm{H}), 1.28(\mathrm{~s}, 3 \mathrm{H})$; ${ }^{13} \mathrm{C}$ NMR $\left(125 \mathrm{MHz}\right.$, DMSO- $\left.d_{6}\right) \delta 187.07,164.49,163.25,136.67$, 131.34, 131.27, 128.84, 114.66, 68.51, 63.72, 21.48, 14.41; HRMS (ESI) $\mathrm{m} / \mathrm{z}$ calcd for $\mathrm{C}_{15} \mathrm{H}_{18} \mathrm{O}_{4} \mathrm{Na}[\mathrm{M}+\mathrm{Na}] 285.1103$, found 285.1107 [M + Na].

(E)-Isopropyl 4-(2-methoxyphenyl)-4-oxobut-2-enoate (10e). Yellow oil (43\%). ${ }^{1} \mathrm{H}$ NMR (500 MHz, DMSO- $\left.d_{6}\right) \delta 7.65(\mathrm{~d}, J=$ $15.5 \mathrm{~Hz}, 1 \mathrm{H}), 7.62-7.57$ (m, 2H), 7.24-7.22 (m, 1H), 7.10-7.07 $(\mathrm{m}, 1 \mathrm{H}), 6.53(\mathrm{~d}, J=15.5 \mathrm{~Hz}, 1 \mathrm{H}), 5.05-5.00(\mathrm{~m}, 1 \mathrm{H}), 3.89(\mathrm{~s}, 3 \mathrm{H})$, $1.27(\mathrm{~s}, 3 \mathrm{H}), 1.26(\mathrm{~s}, 3 \mathrm{H}) ;{ }^{13} \mathrm{C}$ NMR (125 MHz, DMSO- $\left.d_{6}\right)$ $\delta$ 190.64, 164.58, 158.62, 140.58, 134.71, 130.06, 129.73, 126.81, 120.82, 112.70, 68.46, 55.97, 21.46; HRMS (ESI) $\mathrm{m} / \mathrm{z}$ calcd for $\mathrm{C}_{14} \mathrm{H}_{16} \mathrm{O}_{4} \mathrm{Na}[\mathrm{M}+\mathrm{Na}] 271.0946$, found 271.0938 [M + Na]. 
(E)-Isopropyl 4-(3-methoxyphenyl)-4-oxobut-2-enoate (10f). Yellow oil (45\%). ${ }^{1} \mathrm{H}$ NMR $\left(500 \mathrm{MHz}\right.$, DMSO- $\left.d_{6}\right) \delta 7.91(\mathrm{~d}, J=$ $15.5 \mathrm{~Hz}, 1 \mathrm{H}), 7.67-7.61(\mathrm{~m}, 1 \mathrm{H}), 7.54-7.47$ (m, 2H), 7.30-7.28 $(\mathrm{m}, 1 \mathrm{H}), 6.70(\mathrm{~d}, J=15.5 \mathrm{~Hz}, 1 \mathrm{H}), 5.10-5.00(\mathrm{~m}, 1 \mathrm{H}), 3.84(\mathrm{~s}, 3 \mathrm{H})$, $1.29(\mathrm{~s}, 3 \mathrm{H}), 1.28(\mathrm{~s}, 3 \mathrm{H}) ;{ }^{13} \mathrm{C}$ NMR (125 MHz, DMSO- $\left.d_{6}\right)$ $\delta$ 188.92, 164.34, 159.59, 137.42, 136.53, 132.05, 130.16, 121.47, 120.22, 112.82, 68.59, 55.34, 21.43; HRMS (ESI) $\mathrm{m} / \mathrm{z}$ calcd for $\mathrm{C}_{14} \mathrm{H}_{16} \mathrm{O}_{4} \mathrm{Na}[\mathrm{M}+\mathrm{Na}] 271.0946$, found $271.0932[\mathrm{M}+\mathrm{Na}]$.

(E)-Isopropyl 4-(2,5-dimethoxyphenyl)-4-oxobut-2-enoate (10g). Yellow solid (40\%). Mp: 43.5-45.7 ${ }^{\circ} \mathrm{C} .{ }^{1} \mathrm{H}$ NMR $(500 \mathrm{MHz}$, DMSO- $\left.d_{6}\right) \delta 7.66(\mathrm{~d}, J=15.5 \mathrm{~Hz}, 1 \mathrm{H}), 7.24-7.16(\mathrm{~m}, 2 \mathrm{H}), 7.11-$ $7.10(\mathrm{~m}, 1 \mathrm{H}), 6.53(\mathrm{~d}, J=15.5 \mathrm{~Hz}, 1 \mathrm{H}), 5.08-4.99(\mathrm{~m}, 1 \mathrm{H}), 3.84(\mathrm{~s}$, $3 \mathrm{H}), 3.75$ (s, 3H), 1.27 (s, 3H), $1.25(\mathrm{~s}, 3 \mathrm{H}) ;{ }^{13} \mathrm{C}$ NMR $(125 \mathrm{MHz}$, DMSO- $\left.d_{6}\right) \delta 190.20,164.58,153.15,153.00,140.52,129.77$, 127.09, 120.71, 114.34, 113.75, 68.46, 56.44, 55.56, 21.45; HRMS (ESI) $m / z$ calcd for $\mathrm{C}_{15} \mathrm{H}_{18} \mathrm{O}_{5} \mathrm{Na}[\mathrm{M}+\mathrm{Na}] 301.1052$, found $301.1062[\mathrm{M}+\mathrm{Na}]$.

(E)-Isopropyl 4-(3,4-dimethoxyphenyl)-4-oxobut-2-enoate (10h). Yellow solid (41\%). Mp: 65.4-66.8 ${ }^{\circ} \mathrm{C} .{ }^{1} \mathrm{H}$ NMR $(500 \mathrm{MHz}$, DMSO- $\left.d_{6}\right) \delta 7.97(\mathrm{~d}, J=15.5 \mathrm{~Hz}, 1 \mathrm{H}), 7.78-7.76(\mathrm{~m}, 1 \mathrm{H}), 7.51-$ $7.50(\mathrm{~m}, 1 \mathrm{H}), 7.12-7.11(\mathrm{~m}, 1 \mathrm{H}), 6.69$ (d, $J=15.5 \mathrm{~Hz}, 1 \mathrm{H}), 5.12-$ $4.98(\mathrm{~m}, 1 \mathrm{H}), 3.88(\mathrm{~s}, 3 \mathrm{H}), 3.84(\mathrm{~s}, 3 \mathrm{H}), 1.29(\mathrm{~s}, 3 \mathrm{H}), 1.28(\mathrm{~s}, 3 \mathrm{H})$; ${ }^{13} \mathrm{C}$ NMR $\left(125 \mathrm{MHz}\right.$, DMSO- $\left.d_{6}\right) \delta 187.05,164.55,154.06,149.03$, $136.59,131.31,129.04,124.35$, 110.97, 110.38, 68.53, 55.87, 55.54, 21.50; HRMS (ESI) $\mathrm{m} / z$ calcd for $\mathrm{C}_{15} \mathrm{H}_{18} \mathrm{O}_{5} \mathrm{Na}[\mathrm{M}+\mathrm{Na}]$ 301.1052, found 301.1052 [M $+\mathrm{Na}]$.

(E)-Isopropyl 4-(Benzo[d][1,3] dioxol-5-yl)-4-oxobut-2-enoate (10i). Yellow solid (43\%). Mp: 54.4-55.8 ${ }^{\circ} \mathrm{C}$. ${ }^{1} \mathrm{H}$ NMR (500 MHz, DMSO- $\left.d_{6}\right) \delta 7.90(\mathrm{~d}, J=15.5 \mathrm{~Hz}, 1 \mathrm{H}), 7.74-7.72(\mathrm{~m}, 1 \mathrm{H})$, 7.51-7.50 (m, 1H), 7.09-7.08 (m, 1H), 6.66 (d, $J=15.5 \mathrm{~Hz}, 1 \mathrm{H})$, $6.18(\mathrm{~s}, 2 \mathrm{H}), 5.04(\mathrm{~m}, 1 \mathrm{H}), 1.29$ (s, 3H), 1.27 (s, 3H); ${ }^{13} \mathrm{C}$ NMR $(125$ MHz, DMSO- $\left.d_{6}\right) \delta 186.86,164.46,152.42,148.27,136.56,131.51$, 130.79, 126.17, 108.27, 107.62, 102.35, 68.53, 21.49; MS-ESI $(\mathrm{m} / \mathrm{z}): 285.16[\mathrm{M}+\mathrm{Na}]$.

(E)-Isopropyl 4-(2,3-dihydrobenzofuran-5-yl)-4-oxobut-2-enoate (10j). Yellow solid (41\%). Mp: 65.6-66.9 ${ }^{\circ} \mathrm{C}$. ${ }^{1} \mathrm{H}$ NMR (500 MHz, DMSO- $\left.d_{6}\right) \delta 7.97-7.86(\mathrm{~m}, 3 \mathrm{H}), 6.91-6.89(\mathrm{~m}, 1 \mathrm{H}), 6.64(\mathrm{~d}, J$ $=15.5 \mathrm{~Hz}, 1 \mathrm{H}), 5.09-4.97(\mathrm{~m}, 1 \mathrm{H}), 4.66(\mathrm{t}, J=9.0 \mathrm{~Hz}, 2 \mathrm{H}), 3.25(\mathrm{t}$, $J=9.0 \mathrm{~Hz}, 2 \mathrm{H}), 1.27(\mathrm{~s}, 3 \mathrm{H}), 1.26(\mathrm{~s}, 3 \mathrm{H}) ;{ }^{13} \mathrm{C}$ NMR $(125 \mathrm{MHz}$, DMSO- $\left.d_{6}\right) \delta 186.84,164.85,164.53,136.88,131.11,131.07$, 129.32, 128.84, 126.30, 109.18, 72.42, 68.48, 28.25, 21.49; HRMS (ESI) $\mathrm{m} / z$ calcd for $\mathrm{C}_{15} \mathrm{H}_{16} \mathrm{O}_{4} \mathrm{Na}[\mathrm{M}+\mathrm{Na}] 283.0946$, found 283.0954 [M + Na].

(E)-Isopropyl 4-([1,1'-biphenyl]-4-yl)-4-oxobut-2-enoate (10k). Yellow solid (40\%). Mp: 117.9-119.0 ${ }^{\circ} \mathrm{C} .{ }^{1} \mathrm{H}$ NMR $(400 \mathrm{MHz}$, DMSO- $\left.d_{6}\right) \delta$ 7.97-7.95 (m, 2H), 7.87-7.85 (m, 2H), 7.78-7.73 (m, $2 \mathrm{H}), 7.54-7.50(\mathrm{~m}, 2 \mathrm{H}), 7.46-7.42(\mathrm{~m}, 1 \mathrm{H}), 7.25(\mathrm{~d}, J=15.6 \mathrm{~Hz}$, $1 \mathrm{H}), 6.37$ (d, $J=15.6 \mathrm{~Hz}, 1 \mathrm{H}), 4.80(\mathrm{~m}, 1 \mathrm{H}), 1.04(\mathrm{~s}, 3 \mathrm{H}), 1.03$ (s, $3 \mathrm{H})$; MS-ESI $(\mathrm{m} / \mathrm{z}): 317.21[\mathrm{M}+\mathrm{Na}]$.

(E)-Isopropyl 4-oxo-4-(4-phenoxyphenyl) but-2-enoate (10l). Yellow solid (42\%). Mp: 74.5-76.0 ${ }^{\circ} \mathrm{C}$. ${ }^{1} \mathrm{H}$ NMR $(400 \mathrm{MHz}$, DMSO- $\left.d_{6}\right) \delta 8.11-8.05(\mathrm{~m}, 2 \mathrm{H}), 7.91$ (d, $\left.J=15.5 \mathrm{~Hz}, 1 \mathrm{H}\right), 7.53-$ 7.45 (m, 2H), 7.31-7.24 (m, 1H), 7.19-7.14 (m, 2H), 7.11-7.06 $(\mathrm{m}, 2 \mathrm{H}), 6.69(\mathrm{~d}, J=15.5 \mathrm{~Hz}, 1 \mathrm{H}), 5.06-5.04(\mathrm{~m}, 1 \mathrm{H}), 1.29(\mathrm{~s}, 3 \mathrm{H})$, $1.27(\mathrm{~s}, 3 \mathrm{H}) ;{ }^{13} \mathrm{C}$ NMR $\left(125 \mathrm{MHz}, \mathrm{DMSO}-d_{6}\right) \delta 187.51,164.45$, 162.12 , 154.65, 136.60, 131.67, 131.60, 130.76, 130.41, 125.05,
120.24, 117.29, 68.60, 21.50; HRMS (ESI) $\mathrm{m} / \mathrm{z}$ calcd for $\mathrm{C}_{19} \mathrm{H}_{18} \mathrm{O}_{4} \mathrm{Na}[\mathrm{M}+\mathrm{Na}] 333.1103$, found 333.1087 [M + Na].

(E)-Isopropyl 4-(naphthalen-1-yl)-4-oxobut-2-enoate (10m). Yellow oil (43\%). ${ }^{1} \mathrm{H}$ NMR (400 MHz, $\left.\mathrm{CDCl}_{3}\right) \delta 8.51-8.49(\mathrm{~m}, 1 \mathrm{H})$, 8.05-8.03 (m, 1H), 7.92-7.85 (m, 2H), 7.71 (d, $J=15.6 \mathrm{~Hz}, 1 \mathrm{H})$, $7.66-7.50(\mathrm{~m}, 3 \mathrm{H}), 6.75(\mathrm{~d}, J=15.6 \mathrm{~Hz}, 1 \mathrm{H}), 5.18-5.12(\mathrm{~m}, 1 \mathrm{H})$, $1.32(\mathrm{~s}, 3 \mathrm{H}), 1.30$ (s, 3H); HRMS (ESI) $\mathrm{m} / z$ calcd for $\mathrm{C}_{17} \mathrm{H}_{16} \mathrm{O}_{3} \mathrm{Na}$ $[\mathrm{M}+\mathrm{Na}] 291.0997$, found $291.1002[\mathrm{M}+\mathrm{Na}]$.

(E)-Isopropyl 4-(2,4-dichlorophenyl)-4-oxobut-2-enoate (10n). Yellow solid (45\%). Mp: 58.0-60.1 ${ }^{\circ} \mathrm{C} .{ }^{1} \mathrm{H}$ NMR $(400 \mathrm{MHz}$, $\left.\mathrm{CDCl}_{3}\right) \delta$ 7.51-7.44 (m, 3H), 7.37-7.35 (m, 1H), $6.63(\mathrm{~d}, J=$ 16.0 Hz, 1H), 5.18-5.08 (m, 1H), 1.31 (s, 6H), 1.29 (s, 3H); HRMS (ESI) $\mathrm{m} / z$ calcd for $\mathrm{C}_{13} \mathrm{H}_{12} \mathrm{Cl}_{2} \mathrm{O}_{3} \mathrm{Na}[\mathrm{M}+\mathrm{Na}] 309.0061$, found 309.0079 [M + Na].

(E)-Isopropyl 4-(4-nitrophenyl)-4-oxobut-2-enoate (10o). Yellow solid (44\%). Mp: 81.5-82.7 ${ }^{\circ} \mathrm{C} .{ }^{1} \mathrm{H}$ NMR (500 MHz, DMSO- $d_{6}$ ) $\delta 8.42-8.34(\mathrm{~m}, 2 \mathrm{H}), 8.29-8.21(\mathrm{~m}, 2 \mathrm{H}), 7.90(\mathrm{~d}, J=15.5 \mathrm{~Hz}, 1 \mathrm{H})$, $6.74(\mathrm{~d}, J=15.5 \mathrm{~Hz}, 1 \mathrm{H}), 5.09-5.04(\mathrm{~m}, 1 \mathrm{H}), 1.30(\mathrm{~s}, 3 \mathrm{H}), 1.28(\mathrm{~s}$, $3 \mathrm{H}$ ); HRMS (ESI) $\mathrm{m} / z$ calcd for $\mathrm{C}_{13} \mathrm{H}_{12} \mathrm{NO}_{5}[\mathrm{M}-\mathrm{H}] 262.0715$, found 262.0698 [M $-\mathrm{H}]$.

(E)-Isopropyl 4-(4-bromophenyl)-4-oxobut-2-enoate (10p). Yellow solid (41\%). Mp: 101.7-102.5 ${ }^{\circ} \mathrm{C}$. ${ }^{1} \mathrm{H}$ NMR $(500 \mathrm{MHz}$, DMSO- $\left.d_{6}\right) \delta 7.98-7.96(\mathrm{~m}, 2 \mathrm{H}), 7.89(\mathrm{~d}, J=15.5 \mathrm{~Hz}, 1 \mathrm{H}), 7.81-$ $7.79(\mathrm{~m}, 2 \mathrm{H}), 6.71(\mathrm{~d}, J=15.5 \mathrm{~Hz}, 1 \mathrm{H}), 5.10-4.99(\mathrm{~m}, 1 \mathrm{H}), 1.29(\mathrm{~s}$, $3 \mathrm{H}), 1.28(\mathrm{~s}, 3 \mathrm{H}) ;{ }^{13} \mathrm{C}$ NMR $\left(125 \mathrm{MHz}, \mathrm{DMSO}-d_{6}\right) \delta 188.54$, 164.33, 136.32, 135.02, 132.10, 130.82, 128.30, 68.86, 21.49; HRMS (ESI) $m / z$ calcd for $\mathrm{C}_{13} \mathrm{H}_{13} \mathrm{BrO}_{3} \mathrm{Na}[\mathrm{M}+\mathrm{Na}] 318.9946$, found 318.9951 [M+ Na].

(E)-Isopropyl 4-(furan-2-yl)-4-oxobut-2-enoate (10q). Yellow solid (42\%). Mp: 41.7-43.4 ${ }^{\circ} \mathrm{C} .{ }^{1} \mathrm{H}$ NMR (400 MHz, $\left.\mathrm{CDCl}_{3}\right) \delta 7.73$ (d, $J=15.6 \mathrm{~Hz}, 1 \mathrm{H}), 7.70-7.69(\mathrm{~m}, 1 \mathrm{H}), 7.38-7.37$ (m, 1H), 6.96 $(\mathrm{d}, J=15.6 \mathrm{~Hz}, 1 \mathrm{H}), 6.63-6.62(\mathrm{~m}, 1 \mathrm{H}), 5.19-5.10(\mathrm{~m}, 1 \mathrm{H}), 1.33$ $(\mathrm{s}, 6 \mathrm{H}), 1.31(\mathrm{~s}, 1 \mathrm{H}) ;{ }^{13} \mathrm{C}$ NMR $\left(125 \mathrm{MHz}, \mathrm{DMSO}-d_{6}\right) \delta 175.53$, $164.27,151.98,149.63,135.83,131.48,121.50$, 113.27, 68.66, 21.46; HRMS (ESI) $m / z$ calcd for $\mathrm{C}_{10} \mathrm{H}_{10} \mathrm{O}_{4} \mathrm{Na}[\mathrm{M}+\mathrm{Na}] 231.0633$, found $231.0632[\mathrm{M}+\mathrm{Na}]$.

(E)-Isopropyl 4-oxopent-2-enoate (10r). Yellow oil $(42 \%) .{ }^{1} \mathrm{H}$ NMR (400 MHz, $\left.\mathrm{CDCl}_{3}\right) \delta 6.98(\mathrm{~d}, J=16.0 \mathrm{~Hz}, 1 \mathrm{H}), 6.61(\mathrm{~d}, J=$ $16.0 \mathrm{~Hz}, 1 \mathrm{H}), 5.14-5.08(\mathrm{~m}, 1 \mathrm{H}), 2.34(\mathrm{~s}, 3 \mathrm{H})$; MS-ESI $(\mathrm{m} / \mathrm{z})$ : $179.14[\mathrm{M}+\mathrm{Na}]$.

(E)-Isopropyl 4-cyclohexyl-4-oxobut-2-enoate (10s). Yellow oil (37\%). ${ }^{1} \mathrm{H}$ NMR $\left(500 \mathrm{MHz}, \mathrm{CDCl}_{3}\right) \delta 7.14(\mathrm{~d}, J=16.0 \mathrm{~Hz}, 1 \mathrm{H})$, $6.67(\mathrm{~d}, J=16.0 \mathrm{~Hz}, 1 \mathrm{H}), 5.14-5.09(\mathrm{~m}, 1 \mathrm{H}), 2.63-2.57(\mathrm{~m}, 1 \mathrm{H})$, 1.91-1.66 (m, 5H), 1.39-1.22 (m, 11H); ${ }^{13} \mathrm{C}$ NMR (125 MHz, DMSO- $\left.d_{6}\right) \delta 202.34,164.57,138.55,130.46,68.51,47.74,27.75$, 25.37, 24.87, 21.44; MS-ESI $(\mathrm{m} / \mathrm{z}): 247.20$ [M + Na].

(E)-Isopropyl 4-cyclopropyl-4-oxobut-2-enoate (10t). Yellow oil (39\%). ${ }^{1} \mathrm{H}$ NMR (500 MHz, $\left.\mathrm{CDCl}_{3}\right) \delta 7.14(\mathrm{~d}, J=16.0 \mathrm{~Hz}, 1 \mathrm{H})$, $6.69(\mathrm{~d}, J=16.0 \mathrm{~Hz}, 1 \mathrm{H}), 5.14-5.09(\mathrm{~m}, 1 \mathrm{H}), 2.22-2.17(\mathrm{~m}, 1 \mathrm{H})$, 1.29 (s, 3H), 1.28 (s, 3H), 1.18-1.13 (m, 2H), 1.03-0.99 (m, 2H); ${ }^{13} \mathrm{C}$ NMR $\left(125 \mathrm{MHz}, \mathrm{DMSO}-d_{6}\right) \delta 199.58,164.66,139.51,130.71$, $68.60,21.47,19.29,11.71$; HRMS (ESI) $m / z$ calcd for $\mathrm{C}_{10} \mathrm{H}_{14} \mathrm{O}_{3} \mathrm{Na}$ $[\mathrm{M}+\mathrm{Na}] 205.0841$, found 205.0826 [M + Na].

(E)-2-((tert-Butoxycarbonyl) amino) ethyl 4-(4-methoxyphenyl)-4oxobut-2-enoate (11a). White solid (81\%), mp: 93.5-94.7 ${ }^{\circ} \mathrm{C} .{ }^{1} \mathrm{H}$ NMR (500 MHz, DMSO- $\left.d_{6}\right) \delta 8.06-8.05(\mathrm{~m}, 2 \mathrm{H}), 7.99(\mathrm{~d}, J=$ $15.5 \mathrm{~Hz}, 1 \mathrm{H}), 7.11-7.10(\mathrm{~m}, 2 \mathrm{H}), 7.05-7.03$ (m, 1H), 6.69 (d, $J=$ 
$15.5 \mathrm{~Hz}, 1 \mathrm{H}), 4.18-4.16$ (m, 2H), 3.88 (s, 3H), 3.28-3.24 (m, 2H), $1.37(\mathrm{~s}, 9 \mathrm{H}) ;{ }^{13} \mathrm{C}$ NMR $\left(125 \mathrm{MHz}, \mathrm{DMSO}-d_{6}\right) \delta 187.19,164.92$, 164.00, 155.71, 136.85, 131.38, 130.93, 129.01, 114.37, 77.85, 64.07, 55.71, 38.82, 28.19; HRMS (ESI) $\mathrm{m} / \mathrm{z}$ calcd for $\mathrm{C}_{18} \mathrm{H}_{23} \mathrm{NO}_{6} \mathrm{Na}[\mathrm{M}+\mathrm{Na}]$ 372.1423, found 372.1441 [M $+\mathrm{Na}$.

(E)-2-((tert-Butoxycarbonyl) amino) ethyl 4-oxo-4-phenylbut-2enoate (11b). White solid (75\%), mp: 95.5-96.8 ${ }^{\circ} \mathrm{C} .{ }^{1} \mathrm{H}$ NMR $\left(400 \mathrm{MHz}, \mathrm{DMSO}-d_{6}\right) \delta 8.08-8.02(\mathrm{~m}, 2 \mathrm{H}), 7.97(\mathrm{~d}, J=15.6 \mathrm{~Hz}$, $1 \mathrm{H}), 7.75-7.71(\mathrm{~m}, 1 \mathrm{H}), 7.62-7.58(\mathrm{~m}, 2 \mathrm{H}), 7.06-7.03(\mathrm{~m}, 1 \mathrm{H})$, $6.72(\mathrm{~d}, J=15.6 \mathrm{~Hz}, 1 \mathrm{H}), 4.18-4.16(\mathrm{~m}, 2 \mathrm{H}), 3.28-3.24(\mathrm{~m}, 2 \mathrm{H})$, $1.37(\mathrm{~s}, 9 \mathrm{H}) ;{ }^{13} \mathrm{C}$ NMR $\left(125 \mathrm{MHz}, \mathrm{DMSO}-d_{6}\right) \delta 189.33,164.81$, 155.71, 136.78, 136.02, 134.14, 131.59, 129.07, 128.82, 77.85, 64.14, 38.80, 28.19; HRMS (ESI) $m / z$ calcd for $\mathrm{C}_{17} \mathrm{H}_{21} \mathrm{NO}_{5} \mathrm{Na}[\mathrm{M}+$ $\mathrm{Na}$ 3 342.1317, found 342.1320 [M + Na].

(E)-2-((tert-Butoxycarbonyl) amino) ethyl 4-oxo-4-(p-tolyl) but-2enoate (11c). White solid (84\%), mp: 88.7-91.4 ${ }^{\circ} \mathrm{C} .{ }^{1} \mathrm{H}$ NMR (400 MHz, DMSO- $\left.d_{6}\right) \delta$ 7.99-7.95 (m, 3H), 7.41-7.39 (m, 2H), 7.06$7.03(\mathrm{~m}, 1 \mathrm{H}), 6.70(\mathrm{~d}, J=15.6 \mathrm{~Hz}, 1 \mathrm{H}), 4.18-4.15(\mathrm{~m}, 2 \mathrm{H}), 3.28-$ $3.24(\mathrm{~m}, 2 \mathrm{H}), 2.41(\mathrm{~s}, 3 \mathrm{H}), 1.37(\mathrm{~s}, 9 \mathrm{H}) ;{ }^{13} \mathrm{C}$ NMR $(125 \mathrm{MHz}$, DMSO- $\left.d_{6}\right) \delta 188.62,164.85,155.71,144.88,136.80,133.58$, 131.32, 129.65, 128.98, 77.85, 64.12, 38.80, 28.19, 21.21; HRMS (ESI) $\mathrm{m} / z$ calcd for $\mathrm{C}_{18} \mathrm{H}_{23} \mathrm{NO}_{5} \mathrm{Na}[\mathrm{M}+\mathrm{Na}] 356.1474$, found $356.1469[\mathrm{M}+\mathrm{Na}]$.

(E)-2-((tert-butoxycarbonyl) amino) ethyl 4-(4-ethoxyphenyl)-4oxobut-2-enoate (11d). White solid (79\%), mp: 96.5-97.6 ${ }^{\circ} \mathrm{C} .{ }^{1} \mathrm{H}$ NMR (500 MHz, DMSO- $\left.d_{6}\right) \delta 8.05-8.03(\mathrm{~m}, 2 \mathrm{H}), 7.98(\mathrm{~d}, J=$ $15.5 \mathrm{~Hz}, 1 \mathrm{H}), 7.09-7.07$ (m, 2H), 7.05-7.03 (m, 1H), 6.69 (d, $J=$ $15.5 \mathrm{~Hz}, 1 \mathrm{H}), 4.22-4.10(\mathrm{~m}, 4 \mathrm{H}), 3.28-3.25$ (m, 2H), 1.42-1.31 $(\mathrm{m}, 12 \mathrm{H}) ;{ }^{13} \mathrm{C}$ NMR $\left(125 \mathrm{MHz}, \mathrm{DMSO}-d_{6}\right) \delta 187.13,164.92$, 163.31, 155.71, 136.86, 131.38, 130.87, 128.83, 114.71, 77.84, 64.07, 63.76, 38.81, 28.19, 14.43; HRMS (ESI) $\mathrm{m} / \mathrm{z}$ calcd for $\mathrm{C}_{19} \mathrm{H}_{24} \mathrm{NO}_{6}[\mathrm{M}-\mathrm{H}]$ 362.1604, found 362.1595 [M - H].

(E)-2-((tert-Butoxycarbonyl) amino) ethyl 4-(2-methoxyphenyl)-4oxobut-2-enoate (11e). White solid (84\%), mp: 83.6-85.4 ${ }^{\circ} \mathrm{C} .{ }^{1} \mathrm{H}$ NMR (500 MHz, DMSO- $d_{6}$ ) $\delta 7.67$ (d, $\left.J=15.5 \mathrm{~Hz}, 1 \mathrm{H}\right), 7.64-7.55$ $(\mathrm{m}, 2 \mathrm{H}), 7.24-7.22(\mathrm{~m}, 1 \mathrm{H}), 7.11-7.06(\mathrm{~m}, 1 \mathrm{H}), 7.01-7.99(\mathrm{~m}$, $1 \mathrm{H}), 6.55(\mathrm{~d}, J=15.5 \mathrm{~Hz}, 1 \mathrm{H}), 4.16-4.14(\mathrm{~m}, 2 \mathrm{H}), 3.89(\mathrm{~s}, 3 \mathrm{H})$, 3.25-3.22 (m, 2H), 1.35 (s, 9H); ${ }^{13} \mathrm{C}$ NMR (125 MHz, DMSO- $\left.d_{6}\right)$ $\delta 190.84,165.05,158.62,155.67,140.72,134.69,130.00,129.37$, 126.88, 120.81, 112.67, 77.78, 63.89, 55.98, 38.80, 28.15; HRMS (ESI) $m / z$ calcd for $\mathrm{C}_{18} \mathrm{H}_{23} \mathrm{NO}_{6} \mathrm{Na}[\mathrm{M}+\mathrm{Na}] 372.1423$, found $372.1424[\mathrm{M}+\mathrm{Na}]$.

(E)-2-((tert-Butoxycarbonyl) amino) ethyl 4-(3-eethoxyphenyl)-4oxobut-2-enoate (11f). White solid (81\%), mp: 65.7-66.8 ${ }^{\circ} \mathrm{C} .{ }^{1} \mathrm{H}$ NMR (400 MHz, DMSO- $d_{6}$ ) $\delta 7.96$ (d, $\left.J=15.6 \mathrm{~Hz}, 1 \mathrm{H}\right), 7.66-7.64$ (m, 1H), 7.55-7.48 (m, 2H), 7.31-7.28 (m, 1H), 7.06-7.03 (m, $1 \mathrm{H}), 6.71(\mathrm{~d}, J=15.6 \mathrm{~Hz}, 1 \mathrm{H}), 4.18-4.15(\mathrm{~m}, 2 \mathrm{H}), 3.85(\mathrm{~s}, 3 \mathrm{H})$, 3.28-3.24 (m, 2H), $2.50(\mathrm{~s}, 9 \mathrm{H}) ;{ }^{13} \mathrm{C}$ NMR (125 MHz, DMSO- $\left.d_{6}\right)$ $\delta 189.08,164.79,159.64,155.71,137.42,136.78,131.67,130.26$, 121.52, 120.37, 112.89, 77.85, 64.14, 55.43, 38.80, 28.18; MS-ESI $(\mathrm{m} / \mathrm{z}): 372.20[\mathrm{M}+\mathrm{Na}]$.

(E)-2-((tert-Butoxycarbonyl) amino) ethyl 4-(2,5-dimethoxyphenyl)-4-oxobut-2-enoate (11g). Yellow oil (81\%). ${ }^{1} \mathrm{H}$ NMR $(500$ MHz, DMSO- $\left.d_{6}\right) \delta 7.68(\mathrm{~d}, J=15.5 \mathrm{~Hz}, 1 \mathrm{H}), 7.24-7.16(\mathrm{~m}, 2 \mathrm{H})$, 7.10-7.09 (m, 1H), 7.01-6.99 (m, 1H), 6.55 (d, $J=15.5 \mathrm{~Hz}, 1 \mathrm{H})$, 4.16-4.14 (m, 2H), $3.84(\mathrm{~s}, 3 \mathrm{H}), 3.75(\mathrm{~s}, 3 \mathrm{H}), 3.25-3.22(\mathrm{~m}, 2 \mathrm{H})$, $1.36(\mathrm{~s}, 9 \mathrm{H}) ;{ }^{13} \mathrm{C}$ NMR $\left(125 \mathrm{MHz}, \mathrm{DMSO}-d_{6}\right) \delta 190.44,165.06$,
155.69, 153.15, 152.99, 140.66, 129.44, 127.16, 120.69, 114.33, 113.73, 77.81, 63.89, 56.46, 55.60, 38.81, 28.16; HRMS (ESI) $\mathrm{m} / \mathrm{z}$ calcd for $\mathrm{C}_{19} \mathrm{H}_{25} \mathrm{NO}_{7} \mathrm{Na}[\mathrm{M}+\mathrm{Na}] 402.1529$, found $402.1519[\mathrm{M}+$ $\mathrm{Na}$.

(E)-2-((tert-Butoxycarbonyl) amino) ethyl 4-(3,4-dimethoxyphenyl)-4-oxobut-2-enoate (11h). Orange solid (69\%), mp: 100.0-101.7 ${ }^{\circ} \mathrm{C} .{ }^{1} \mathrm{H}$ NMR (400 MHz, DMSO- $\left.d_{6}\right) \delta 8.02(\mathrm{~d}, J=$ $15.6 \mathrm{~Hz}, 1 \mathrm{H}), 7.80-7.77$ (m, 1H), 7.53-7.52 (m, 1H), 7.13-7.11 (m, 1H), 7.06-7.03 (m, 1H), 6.71 (d, $J=15.6 \mathrm{~Hz}, 1 \mathrm{H}), 4.18-4.16$ $(\mathrm{m}, 2 \mathrm{H}), 3.88(\mathrm{~s}, 3 \mathrm{H}), 3.85(\mathrm{~s}, 3 \mathrm{H}), 3.28-3.24(\mathrm{~m}, 2 \mathrm{H}), 1.37(\mathrm{~s}, 9 \mathrm{H})$; ${ }^{13} \mathrm{C}$ NMR $\left(125 \mathrm{MHz}, \mathrm{DMSO}-d_{6}\right) \delta 187.08,164.95,155.71,154.10$, $149.05,136.73,130.91,129.03,124.35,110.99,110.42,77.84$, 64.05, 55.90, 55.56, 38.81, 28.19; HRMS (ESI) $\mathrm{m} / \mathrm{z}$ calcd for $\mathrm{C}_{19} \mathrm{H}_{25} \mathrm{NO}_{7} \mathrm{Na}[\mathrm{M}+\mathrm{Na}]$ 402.1529, found $402.1540[\mathrm{M}+\mathrm{Na}]$.

(E)-2-((tert-Butoxycarbonyl) amino) ethyl 4-(benzo[d][1,3] dioxol-5-yl)-4-oxobut-2-enoate (11i). Brown solid (68\%), mp: 115.0-117.4 ${ }^{\circ} \mathrm{C} .{ }^{1} \mathrm{H}$ NMR (400 MHz, DMSO- $\left.d_{6}\right) \delta 7.96(\mathrm{~d}, J=$ $15.6 \mathrm{~Hz}, 1 \mathrm{H}), 7.76-7.73(\mathrm{~m}, 1 \mathrm{H}), 7.52-7.51(\mathrm{~m}, 1 \mathrm{H}), 7.11-7.09$ $(\mathrm{m}, 1 \mathrm{H}), 7.06-7.03(\mathrm{~m}, 1 \mathrm{H}), 6.68(\mathrm{~d}, J=15.6 \mathrm{~Hz}, 1 \mathrm{H}), 6.18(\mathrm{~s}, 2 \mathrm{H})$, 4.17-4.14 (m, 2H), 3.28-3.24 (m, 2H), 1.37 (s, 9H); MS-ESI $(\mathrm{m} / \mathrm{z})$ : $386.16[\mathrm{M}+\mathrm{Na}]$.

(E)-2-((tert-Butoxycarbonyl) amino) ethyl 4-(2,3-dihydrobenzofuran-5-yl)-4-oxobut-2-enoate (11j). White solid (67\%), mp: 106.0-107.6 ${ }^{\circ} \mathrm{C} .{ }^{1} \mathrm{H}$ NMR (400 MHz, DMSO- $\left.d_{6}\right) \delta 8.00-7.96(\mathrm{~m}$, $2 \mathrm{H}), 7.93-7.90(\mathrm{~m}, 1 \mathrm{H}), 7.06-7.03(\mathrm{~m}, 1 \mathrm{H}), 6.94-6.92(\mathrm{~m}, 1 \mathrm{H})$, $6.68(\mathrm{~d}, J=15.6 \mathrm{~Hz}, 1 \mathrm{H}), 4.68(\mathrm{t}, J=8.8 \mathrm{~Hz}, 2 \mathrm{H}), 4.17-4.15(\mathrm{~m}$, 2H), 3.29-3.24 (m, 4H), 1.37 (s, 9H); ${ }^{13} \mathrm{C}$ NMR (125 MHz, DMSO$\left.d_{6}\right) \delta 186.90,164.95,164.92,155.71,137.09,131.12,130.72$, 129.32, 128.92, 126.33, 109.22, 77.84, 72.46, 64.06, 38.81, 28.26, 28.19; HRMS (ESI) $m / z$ calcd for $\mathrm{C}_{19} \mathrm{H}_{23} \mathrm{NO}_{6} \mathrm{Na}[\mathrm{M}+\mathrm{Na}]$ 384.1423, found 384.1416 [M + Na].

(E)-2-((tert-Butoxycarbonyl) amino) ethyl 4-([1,1'-biphenyl]-4-yl)4-oxobut-2-enoate (11k). Yellow solid (62\%), mp: 87.4-89.1 ${ }^{\circ} \mathrm{C}$. ${ }^{1} \mathrm{H}$ NMR (400 MHz, DMSO- $\left.d_{6}\right) \delta 8.16-8.14(\mathrm{~m}, 2 \mathrm{H}), 8.03(\mathrm{~d}, J=$ $15.6 \mathrm{~Hz}, 1 \mathrm{H}), 7.91-7.89(\mathrm{~m}, 2 \mathrm{H}), 7.81-7.76(\mathrm{~m}, 2 \mathrm{H}), 7.57-7.51$ $(\mathrm{m}, 2 \mathrm{H}), 7.51-7.44(\mathrm{~m}, 1 \mathrm{H}), 7.08-7.05(\mathrm{~m}, 1 \mathrm{H}), 6.75(\mathrm{~d}, J=$ $15.6 \mathrm{~Hz}, 1 \mathrm{H}), 4.20-4.17$ (m, 2H), 3.30-3.25 (m, 2H), 1.38 (s, 9H); ${ }^{13} \mathrm{C}$ NMR (125 MHz, DMSO- $d_{6}$ ) $\delta 188.70,164.85,155.71,145.43$, 138.64, 136.78, 134.86, 131.52, 129.62, 129.16, 129.11, 128.65, 127.22, 127.08, 127.05, 77.86, 64.15, 38.82, 28.19; MS-ESI $(\mathrm{m} / \mathrm{z})$ : $418.15[\mathrm{M}+\mathrm{Na}]$.

(E)-2-((tert-Butoxycarbonyl) amino) ethyl 4-oxo-4-(4phenoxyphenyl) but-2-enoate (11l). Brown solid (60\%), mp: 76.4-78.7 ${ }^{\circ} \mathrm{C} .{ }^{1} \mathrm{H}$ NMR (500 MHz, DMSO- $\left.d_{6}\right) \delta 8.10-8.08(\mathrm{~m}, 2 \mathrm{H})$, 7.97 (d, $J=15.5 \mathrm{~Hz}, 1 \mathrm{H}), 7.50-7.47(\mathrm{~m}, 2 \mathrm{H}), 7.29-7.28(\mathrm{~m}, 1 \mathrm{H})$, 7.22-7.13 (m, 2H), 7.10-7.08 (m, 2H), 7.05-7.03 (m, 1H), 6.71 (d, $J=15.5 \mathrm{~Hz}, 1 \mathrm{H}), 4.18-4.16(\mathrm{~m}, 2 \mathrm{H}), 3.28-3.24(\mathrm{~m}, 2 \mathrm{H}), 1.37(\mathrm{~s}$, $9 \mathrm{H}) ;{ }^{13} \mathrm{C}$ NMR $\left(125 \mathrm{MHz}, \mathrm{DMSO}-d_{6}\right) \delta 187.50,164.85,162.16$, $155.70,154.64,136.71,131.59,131.27,130.75,130.41,125.06$, 120.24, 117.29, 77.84, 64.10, 38.81, 28.18; MS-ESI $(\mathrm{m} / \mathrm{z}): 434.19$ $[\mathrm{M}+\mathrm{Na}]$.

(E)-2-((tert-Butoxycarbonyl) amino) ethyl 4-(naphthalen-1-yl)-4oxobut-2-enoate (11m). Yellow solid (57\%), mp: 74.7-76.0 ${ }^{\circ} \mathrm{C}$. ${ }^{1} \mathrm{H}$ NMR $\left(400 \mathrm{MHz}\right.$, DMSO- $\left.d_{6}\right) \delta 8.92-8.90(\mathrm{~m}, 1 \mathrm{H}), 8.46-8.44(\mathrm{~m}$, $1 \mathrm{H}), 8.24-8.19(\mathrm{~m}, 2 \mathrm{H}), 8.08-8.02(\mathrm{~m}, 4 \mathrm{H}), 7.75(\mathrm{~d}, J=15.6 \mathrm{~Hz}$, $1 \mathrm{H}), 7.72-7.58(\mathrm{~m}, 6 \mathrm{H}), 7.42(\mathrm{~d}, J=12.0 \mathrm{~Hz}, 1 \mathrm{H}), 7.04-7.01(\mathrm{~m}$, $1 \mathrm{H}), 6.83-6.81(\mathrm{~m}, 1 \mathrm{H}), 6.64(\mathrm{~d}, J=15.6 \mathrm{~Hz}, 1 \mathrm{H}), 6.37$ (d, $J=$ 
12.0 Hz, 1H), 4.18-4.15 (m, 2H), 3.89-3.86 (m, 2H), 3.26-3.24 (m, 2H), 3.04-3.00 (m, 2H), 1.35 (s, 9H), 1.34 (s, 9H); ${ }^{13} \mathrm{C}$ NMR $\left(125 \mathrm{MHz}, \mathrm{DMSO}-d_{6}\right) \delta 193.07,164.83,155.69,140.06,133.74$, 133.45, 132.10, 129.81, 129.71, 128.73, 128.21, 126.77, 125.05, 124.84, 77.82, 64.17, 38.77, 28.16; MS-ESI $(\mathrm{m} / \mathrm{z}): 392.20[\mathrm{M}+\mathrm{Na}]$.

(E)-2-((tert-Butoxycarbonyl) amino) ethyl 4-(2,4-dichlorophenyl)4-oxobut-2-enoate (11n). Yellow solid (56\%), mp: 54.6-56.3 ${ }^{\circ} \mathrm{C}$. ${ }^{1} \mathrm{H}$ NMR (400 MHz, DMSO- $\left.d_{6}\right) \delta 7.82-7.81(\mathrm{~m}, 1 \mathrm{H}), 7.69-7.67(\mathrm{~m}$, $1 \mathrm{H}), 7.62-7.59(\mathrm{~m}, 1 \mathrm{H}), 7.41(\mathrm{~d}, J=16.0 \mathrm{~Hz}, 1 \mathrm{H}), 7.02-6.99(\mathrm{~m}$, $1 \mathrm{H}), 6.52(\mathrm{~d}, J=16.0 \mathrm{~Hz}, 1 \mathrm{H}), 4.16-4.13(\mathrm{~m}, 2 \mathrm{H}), 3.24-3.20(\mathrm{~m}$, 2H), 1.35 (s, 9H); ${ }^{13} \mathrm{C}$ NMR (125 MHz, DMSO- $\left.d_{6}\right) \delta$ 188.53, $164.73,155.69$, 136.41, 135.02, 132.12, 130.79, 128.37, 77.85, 64.15 , 38.79, 28.18; HRMS (ESI) $m / z$ calcd for $\mathrm{C}_{17} \mathrm{H}_{19} \mathrm{Cl}_{2} \mathrm{NO}_{5} \mathrm{Na}$ $[\mathrm{M}+\mathrm{Na}] 410.0538$, found $410.0560[\mathrm{M}+\mathrm{Na}]$.

(E)-2-((tert-Butoxycarbonyl) amino) ethyl 4-(4-nitrophenyl)-4oxobut-2-enoate (11o). Yellow solid (55\%), mp: 86.6-88.5 ${ }^{\circ} \mathrm{C}$. ${ }^{1} \mathrm{H}$ NMR (400 MHz, DMSO- $d_{6}$ ) $\delta 8.43-8.34(\mathrm{~m}, 2 \mathrm{H}), 8.27-8.25(\mathrm{~m}$, $2 \mathrm{H}), 7.96(\mathrm{~d}, J=15.6 \mathrm{~Hz}, 1 \mathrm{H}), 7.06-7.03(\mathrm{~m}, 1 \mathrm{H}), 6.76(\mathrm{~d}, J=$ 15.6 Hz, 1H), 4.19-4.17 (m, 2H), 3.28-3.24 (m, 2H), 1.37 (s, 9H); HRMS (ESI) $m / z$ calcd for $\mathrm{C}_{17} \mathrm{H}_{19} \mathrm{~N}_{2} \mathrm{O}_{7}[\mathrm{M}-\mathrm{H}] 363.1193$, found $363.1201[\mathrm{M}-\mathrm{H}]$.

(E)-2-((tert-Butoxycarbonyl) amino) ethyl 4-(4-bromophenyl)-4oxobut-2-enoate (11p). Yellow solid (53\%), mp: 86.6-88.5 ${ }^{\circ} \mathrm{C}$. ${ }^{1} \mathrm{H}$ NMR (500 MHz, DMSO- $\left.d_{6}\right) \delta 7.99-7.97(\mathrm{~m}, 2 \mathrm{H}), 7.94(\mathrm{~d}, J=$ $15.5 \mathrm{~Hz}, 1 \mathrm{H}), 7.81-7.79(\mathrm{~m}, 2 \mathrm{H}), 7.05-7.03(\mathrm{~m}, 1 \mathrm{H}), 6.73(\mathrm{~d}, J=$ $15.5 \mathrm{~Hz}, 1 \mathrm{H}), 4.18-4.16$ (m, 2H), 3.28-3.24 (m, 2H), 1.37 (s, 9H); ${ }^{13} \mathrm{C}$ NMR $\left(125 \mathrm{MHz}\right.$, DMSO- $\left.d_{6}\right) \delta 188.53,164.73,155.69,136.41$, 135.02, 132.12, 130.79, 128.37, 77.85, 64.15, 38.79, 28.18; MS-ESI $(\mathrm{m} / \mathrm{z}): 420.10[\mathrm{M}+\mathrm{Na}]$.

(E)-2-((tert-Butoxycarbonyl) amino) ethyl 4-(furan-2-yl)-4oxobut-2-enoate (11q). White solid (55\%), mp: 86.6-88.5 ${ }^{\circ} \mathrm{C} .{ }^{1} \mathrm{H}$ NMR (400 MHz, DMSO- $d_{6}$ ) $\delta$ 8.16-8.15 (m, 1H), 7.84-7.83 (m, $1 \mathrm{H}), 7.78(\mathrm{~d}, J=15.6 \mathrm{~Hz}, 1 \mathrm{H}), 7.04-7.01(\mathrm{~m}, 1 \mathrm{H}), 6.84-6.82(\mathrm{~m}$, $1 \mathrm{H}), 6.78(\mathrm{~d}, J=15.6 \mathrm{~Hz}, 1 \mathrm{H}), 4.18-4.15(\mathrm{~m}, 2 \mathrm{H}), 3.27-3.23(\mathrm{~m}$, 2H), 1.37 (s, 9H); ${ }^{13} \mathrm{C}$ NMR (125 MHz, DMSO- $\left.d_{6}\right) \delta 175.54$, 164.69, 155.70, 151.97, 149.77, 149.74, 136.01, 131.08, 121.66, 121.62, 113.29, 77.85, 64.10, 38.79, 28.18; HRMS (ESI) $\mathrm{m} / z$ calcd for $\mathrm{C}_{15} \mathrm{H}_{19} \mathrm{NO}_{6} \mathrm{Na}[\mathrm{M}+\mathrm{Na}]$ 332.1110, found $332.1105[\mathrm{M}+\mathrm{Na}]$.

(E)-2-((tert-Butoxycarbonyl) amino) ethyl 4-oxopent-2-enoate (11r). White solid (51\%), mp: 96.7-98.6 ${ }^{\circ} \mathrm{C} .{ }^{1} \mathrm{H}$ NMR $(400$ MHz, DMSO- $\left.d_{6}\right) \delta 7.02-7.00(\mathrm{~m}, 1 \mathrm{H}), 6.90(\mathrm{~d}, J=16.0 \mathrm{~Hz}, 1 \mathrm{H})$, $6.72(\mathrm{~d}, J=16.0 \mathrm{~Hz}, 1 \mathrm{H}), 4.15-4.12(\mathrm{~m}, 2 \mathrm{H}), 3.24-3.20(\mathrm{~m}, 2 \mathrm{H})$, $2.35(\mathrm{~s}, 3 \mathrm{H}), 1.37(\mathrm{~s}, 9 \mathrm{H}) ;{ }^{13} \mathrm{C}$ NMR (125 MHz, DMSO- $\left.d_{6}\right)$ $\delta$ 198.33, 165.15, 155.67, 140.21, 131.14, 77.84, 63.99, 38.77, 28.19, 27.88; HRMS (ESI) $m / z$ calcd for $\mathrm{C}_{12} \mathrm{H}_{19} \mathrm{NO}_{5} \mathrm{Na}[\mathrm{M}+\mathrm{Na}]$ 280.1161 , found $280.1162[\mathrm{M}+\mathrm{Na}]$.

(E)-2-((tert-Butoxycarbonyl) amino) ethyl 4-cyclohexyl-4-oxobut2-enoate (11s). Yellow solid (48\%), mp: 70.1-72.8 ${ }^{\circ} \mathrm{C} .{ }^{1} \mathrm{H}$ NMR $\left(500 \mathrm{MHz}, \mathrm{CDCl}_{3}\right) \delta 7.19(\mathrm{~d}, J=16.0 \mathrm{~Hz}, 1 \mathrm{H}), 6.70(\mathrm{~d}, J=16.0 \mathrm{~Hz}$, $1 \mathrm{H}), 4.79(\mathrm{~s}, 1 \mathrm{H}), 4.27-4.25(\mathrm{~m}, 2 \mathrm{H}), 3.45-3.44(\mathrm{~m}, 2 \mathrm{H}), 2.61-2.56$ (m, 1H), 1.88-1.79 (m, 5H), 1.44 (s, 9H), 1.40-1.19 (m, 5H); MSESI $(m / z): 348.22[\mathrm{M}+\mathrm{Na}]$.

(E)-2-((tert-Butoxycarbonyl) amino) ethyl 4-cyclopropyl-4oxobut-2-enoate (11t). White solid (47\%), mp: 70.1-73.4 ${ }^{\circ} \mathrm{C} .{ }^{1} \mathrm{H}$ NMR $\left(500 \mathrm{MHz}, \mathrm{CDCl}_{3}\right) \delta 7.19(\mathrm{~d}, J=16.0 \mathrm{~Hz}, 1 \mathrm{H}), 6.72(\mathrm{~d}, J=$ $16.0 \mathrm{~Hz}, 1 \mathrm{H}), 4.79$ (s, 1H), 4.28-4.26 (m, 2H), 3.45-3.44 (m, 2H), 2.22-2.17 (m, 1H), $1.44(\mathrm{~s}, 9 \mathrm{H}), 1.21-1.14(\mathrm{~m}, 2 \mathrm{H}), 1.06-1.02$ $(\mathrm{m}, 2 \mathrm{H}) ;{ }^{13} \mathrm{C}$ NMR $\left(125 \mathrm{MHz}, \mathrm{DMSO}-d_{6}\right) \delta 199.61,165.08,155.68$, 139.64, 130.24, 77.83, 63.99, 38.77, 19.39, 11.74; HRMS (ESI) $m / z$ calcd for $\mathrm{C}_{14} \mathrm{H}_{21} \mathrm{NO}_{5} \mathrm{Na}[\mathrm{M}+\mathrm{Na}] 306.1317$, found 306.1309 $[\mathrm{M}+\mathrm{Na}]$.

\section{In vitro protein kinase assay ${ }^{12}$}

The inhibition rates and $\mathrm{IC}_{50}$ values of target compounds were determined by a non-radioactive assay using Promega 'Kinase Glo’ plus Luminescent Kinase assay kit. The assay was carried out in a 96-well plate and the reaction mixture was prepared: 3 $\mu \mathrm{M} \mathrm{PknB}^{12}$ in buffer (25 mL Tris- $\mathrm{HCl} \mathrm{pH} \mathrm{7.4,} 5 \mathrm{mM} \mathrm{MgCl}_{2}$, $2 \mathrm{mM} \mathrm{MnCl}_{2}$ ) containing the compound at various concentrations. Following inculation at $4{ }^{\circ} \mathrm{C}$ for $30 \mathrm{~min}$, ATP was added to the reaction buffer at the final concentration of $100 \mu \mathrm{M}$, and the plates were conducted at $37{ }^{\circ} \mathrm{C}$ for 3 hours. Multilabel Plate Reader (PE Envision) was used to measure the intensity of luminescence signal with addition of $50 \mu \mathrm{L}$ Kinase Glo reagent. The inhibition rates were calculated by the following formula and the $\mathrm{IC}_{50}$ values were calculated using the GraphPad Prism5 software.

$$
\text { Inhibition rate }(\%)=\frac{\Delta \mathrm{LN}-\Delta \mathrm{LS}}{\Delta \mathrm{LN}-\Delta \mathrm{LP}} \times 100 \% .
$$

$\Delta \mathrm{LN}$ : luminescence intensity of negative control; $\Delta \mathrm{LS}$ : luminescence intensity of sample; $\Delta$ LP: luminescence intensity of positive control.

\section{Conflict of interest}

The authors declare no competing financial interests.

\section{Acknowledgements}

This work was supported by the National Science and Technology Project of China (No. 2014ZX09201001-011), the National Natural Science Foundation of China (No. 81373452, 81302644, 81473098, 81473099 and 30970038), and the National Infrastructure of Microbial Resources (No. NIMR-2016-03). Liyan $\mathrm{Yu}$ is supported by Xiehe Scholar.

\section{Notes and references}

1 P. Barthe, G. V. Mukamolova, C. Roumestand and M. CohenGonsaud, Structure, 2010, 18, 606-615.

2 C. M. Kang, D. W. Abbott, S. T. Park, C. C. Dascher, L. C. Cantley and R. N. Husson, Genes Dev., 2005, 19, 16921704.

3 K. Sharma, M. Gupta, A. Krupa, N. Srinivasan and Y. Singh, FEBS J., 2006, 273, 2711-2721.

4 A. Dasgupta, P. Datta, M. Kundu and J. Basu, Microbiology, 2006, 152, 493-504.

5 P. Fernandez, B. Saint-Joanis, N. Barilone, M. Jackson, B. Gicquel, S. T. Cole and P. M. Alzari, J. Bacteriol., 2006, 188, 7778-7784.

6 M. Ortiz-Lombardía, F. Pompeo, B. Boitel and P. Alzari, J. Biol. Chem., 2003, 278, 13094-13100. 
7 A. Narayan, P. Sachdeva, K. Sharma, A. K. Saini, A. K. Tyagi and Y. Singh, Physiol. Genomics, 2007, 29, 66-75.

8 A. Villarino, R. Duran, A. Wehenkel, P. Fernandez, P. England, P. Brodin, S. T. Cole, U. Zimny-Arndt, P. R. Jungblut, C. Cerveñansky and P. M. Alzari, J. Mol. Biol., 2005, 350, 953-963.

9 T. A. Young, B. Delagoutte, J. A. Endrizzi, A. M. Falick and T. Alber, Nat. Struct. Biol., 2003, 10, 168-174.

10 A. Seal, P. Yogeeswari, D. Sriram, O. S. D. D. Consortium and D. J. Wild, J. Cheminf., 2013, 14(5), 2-11.

11 Y. Xing, B. Huang, J. Xu, L. L. Zhao, S. Y. Si, Y. C. Wang, X. F. You and L. Y. Yu, Microbiology, 2014, 41, 646-653.

12 Q. Zhai, J. Pang, G. Li, C. Li, X. Yang, L. Yu, Y. Wang, J. Li and X. You, Acta Pharm. Sin. B, 2015, 5, 467-472.
13 A. Koul, E. Arnoult, N. Lounis, J. Guillemont and K. Andries, Nature, 2011, 469, 483-490.

14 S. Žari, M. Kudrjashova, T. Pehk, M. Lopp and T. Kanger, Org. Lett., 2014, 16, 1740-1743.

15 A. J. Hirsh, B. F. Molino, J. Zhang, N. Astakhova, W. B. Geiss, B. J. Sargent, B. D. Swenson, A. Usyatinsky, M. J. Wyle, R. C. Boucher, R. T. Smith, A. Zamurs and M. R. Johnson, J. Med. Chem., 2006, 49, 4098-4115.

16 N. V. Tolstoluzhsky, N. Y. Gorobets, N. N. Kolos and S. M. Desenko, J. Comb. Chem., 2008, 10, 893-896.

17 C. Srinivas, C. M. Haricharan Raju and P. V. R. Acharyulu, Org. Process Res. Dev., 2004, 8, 291-292. 